\title{
Dual-polarization radar rainfall estimation in Korea according to raindrop shapes obtained by using a 2-D video disdrometer
}

\author{
Hae-Lim Kim ${ }^{1}$, Mi-Kyung Suk ${ }^{1}$, Hye-Sook Park ${ }^{2}$, Gyu-Won Lee ${ }^{3}$, and Jeong-Seok Ko ${ }^{1}$ \\ ${ }^{1}$ Radar Analysis Division, Weather Radar Center, Korea Meteorological Administration, Seoul, South Korea \\ ${ }^{2}$ Satellite Analysis Division, National Meteorological Satellite Center, Korea Meteorological \\ Administration, Seoul, South Korea \\ ${ }^{3}$ Department of Atmospheric Sciences, Kyungpook National University, Daegu, South Korea \\ Correspondence to: Hae-Lim Kim (hlk0919@korea.kr)
}

Received: 18 January 2016 - Published in Atmos. Meas. Tech. Discuss.: 27 January 2016

Revised: 25 July 2016 - Accepted: 25 July 2016 - Published: 22 August 2016

\begin{abstract}
Polarimetric measurements are sensitive to the sizes, concentrations, orientations, and shapes of raindrops. Thus, rainfall rates calculated from polarimetric radar are influenced by the raindrop shapes and canting. The mean raindrop shape can be obtained from long-term raindrop size distribution (DSD) observations, and the shapes of raindrops can play an important role in polarimetric rainfall algorithms based on differential reflectivity $\left(Z_{\mathrm{DR}}\right)$ and specific differential phase $\left(K_{\mathrm{DP}}\right)$. However, the mean raindrop shape is associated with the variation of the DSD, which can change depending on precipitation types and climatic regimes. Furthermore, these relationships have not been studied extensively on the Korean Peninsula. In this study, we present a method to find optimal polarimetric rainfall algorithms for the Korean Peninsula by using data provided by both a twodimensional video disdrometer (2DVD) and the Bislsan Sband dual-polarization radar. First, a new axis-ratio relation was developed to improve radar rainfall estimations. Second, polarimetric rainfall algorithms were derived by using different axis-ratio relations. The rain gauge data were used to represent the ground truth situation, and the estimated radar-point hourly mean rain rates obtained from the different polarimetric rainfall algorithms were compared with the hourly rain rates measured by a rain gauge. The daily calibration biases of horizontal reflectivity $\left(Z_{\mathrm{H}}\right)$ and differential reflectivity $\left(Z_{\mathrm{DR}}\right)$ were calculated by comparing $Z_{\mathrm{H}}$ and $Z_{\mathrm{DR}}$ radar measurements with the same parameters simulated by the 2DVD. Overall, the derived new axis ratio was similar to the existing axis ratio except for both small particles $(\leq 2 \mathrm{~mm})$ and large particles $(\geq 5.5 \mathrm{~mm})$. The shapes of
\end{abstract}

raindrops obtained by the new axis-ratio relation carried out with the 2DVD were more oblate than the shapes obtained by the existing relations. The combined polarimetric rainfall relations using $Z_{\mathrm{DR}}$ and $K_{\mathrm{DP}}$ were more efficient than the single-parameter rainfall relation for estimated 2DVD rainfall; however, the $R\left(Z_{\mathrm{H}}, Z_{\mathrm{DR}}\right)$ algorithm showed the best performance for radar rainfall estimations, because the rainfall events used in the analysis consisted mainly of weak precipitation and $K_{\mathrm{DP}}$ is relatively noisy at lower rain rates $\left(\leq 10 \mathrm{~mm} \mathrm{~h}^{-1}\right)$. Some of the polarimetric rainfall algorithms can be further improved by new axis-ratio relations.

\section{Introduction}

Radar is a very useful monitoring tool for extreme weather forecasting, flood forecasting, and rainfall estimations because of its high spatial and temporal resolution. In particular, dual-polarization radar that provides information on the reflectivity $\left(Z_{\mathrm{H}}\right)$, differential reflectivity $\left(Z_{\mathrm{DR}}\right)$, differential phase $\left(\Phi_{\mathrm{DP}}\right)$, specific differential phase $\left(K_{\mathrm{DP}}\right)$, and cross-correlation coefficient $\left(\rho_{h v}\right)$ can distinguish precipitation types by means of backscatter and the differential propagation phase of hydrometeors. Dual-polarization radar can also be used to obtain more information about the raindrop size distribution (DSD), and this in turn can help to reduce the impact of DSD variability on rainfall estimations (Cifelli et al., 2011). The DSD can be characterized by parameters such as the diameter, concentration, orientation, and shape. Disdrometers and aircraft imaging investigations have been 
widely used to study the DSD variability especially as a function of the rainfall rate (Bringi et al., 2003). Polarimetric parameters are sensitive to the DSD properties. Rainfall rates estimated from polarimetric radar measurements are affected by the mean shape of raindrops and canting (Brandes et al., 2002).

The average shape of a raindrop can be inferred from its size through application of a shape-size relationship for a raindrop. Some researchers have attempted to produce the mean shape of raindrops. Keenan et al. (2001); Brandes et al. (2002); Thurai and Bringi (2005); and Marzuki et al. (2013) derived empirical relations from observational data, and Pruppacher and Beard (1970); Green (1975), and Beard and Chuang (1987) investigated the shape of raindrops falling under the influence of gravity. These raindrop axisratio relations play an important role in the derivation of polarimetric radar rainfall algorithms that use $Z_{\mathrm{DR}}$ and $K_{\mathrm{DP}}$ (Jameson, 1983, 1985; Gorgucci et al., 2001). Polarimetric rainfall algorithm can be derived from long-term DSD measurements. However, the derivation of new empirical algorithms based on long-term DSD data is still challenging for different climatological environments.

Several different polarimetric rainfall algorithms have been developed by assuming raindrop shapes (Sachidananda and Zrnić, 1987; Chandrasekar et al., 1990; Ryzhkov and Zrnić, 1995; Gorgucci et al., 2001). However, radar rainfall estimations are affected by the following two different sources of errors: (i) errors in radar measurements such as from attenuation, bright bands, ground clutter, and calibration bias of $Z_{\mathrm{H}}$ and $Z_{\mathrm{DR}}$ (Zawadzki, 1984; Villarini and Krajewski, 2010; Sebastianelli et al., 2013) and (ii) errors in the conversion of the radar measurements into rainfall rates at the ground level. In addition, the error is also related to the gamma assumption on the retrieve of the rain rate from dualpolarization radar measurements (Adirosi et al., 2014). The DSDs variability affects the accuracy of radar-derived rainfall (Maki et al., 2005). Many earlier studies have explained the variability in the DSD by evoking both different storm types and climatic regimes, and variations of the DSD are known to be caused by climatological and physical factors (e.g., Ulbrich, 1983; Tokay and Short, 1996; Bringi et al., 2003). Variations in time and space of the DSD are associated with changes in microphysical processes such as evaporation, break-up, coalescence, and condensation. They can be also due to the variation of vertical air motion (Marzuki et al., 2013).

Radar measurements often suffer from the system biases of $Z_{\mathrm{H}}$ and $Z_{\mathrm{DR}}$, and thus, accurate measurement and calibration of $Z_{\mathrm{H}}$ and $Z_{\mathrm{DR}}$ values are necessary to achieve accurate radar rainfall estimations (Park and Lee, 2010). An assessment of the calibration bias of polarimetric radar is possible by monitoring the hardware stability, and $Z_{\mathrm{H}}$ and $Z_{\mathrm{DR}}$ measurements can be corrected by using ground validation equipment such as a disdrometer. Joss et al. (1968) calibrated radar reflectivity by using the vertical profile of reflectivity and disdrometer-inferred $Z_{\mathrm{H}}$. The radar reflectivity was calibrated by comparisons between the radar and disdrometer reflectivity to check the calibration of the WSR-88D (weather surveillance radars - 1988 Doppler) at Greer, South Carolina (Ulbrich and Lee, 1999). Goddard et al. (1982) and Goddard and Cherry (1984) compared radar results with disdrometer results by using the axis-ratio relations of Pruppacher and Beard (1970) and Pruppacher and Pitter (1971), respectively; they found that radar measures of $Z_{\mathrm{DR}}$ were 0.3 and $0.1 \mathrm{~dB}$ lower than the disdrometer estimates. In addition to disdrometers, there are various other ways to correct biases in radar data, such as by using the $Z_{\mathrm{H}}-K_{\mathrm{DP}}$ implementation of the self-consistency principle, vertically pointing measurements, and comparisons of measured data and the mean $Z_{\mathrm{H}}-Z_{\mathrm{DR}}$ relationship (Kwon et al., 2015). Moreover, a variety of radar calibration methods were introduced in Atlas (2002).

In this study, we computed the mean axis-ratio relation and developed several polarimetric rainfall algorithms by using two-dimensional video disdrometer (2DVD) measurements collected from September 2011 to October 2012 in Daegu, Korea. Specifically, three raindrop shape assumptions (Pruppacher and Beard, 1970; Beard and Chuang, 1987; Brandes et al., 2002) and the newly derived axis-ratio relation from 2DVD data were used to derive polarimetric rainfall retrieval algorithms. The $Z_{\mathrm{H}}$ and $Z_{\mathrm{DR}}$ biases of Bislsan dualpolarization radar were calibrated by comparing them with simulated $Z_{\mathrm{H}}$ and $Z_{\mathrm{DR}}$ values obtained from the 2DVD. Improvements in the quantitative rainfall estimations were achieved by applying the $Z_{\mathrm{H}}$ and $Z_{\mathrm{DR}}$ calibration biases. In Sect. 2, the data used in this study are described. The methodology for 2DVD data quality control, derivation of the raindrop-axis ratio from 2DVD data, and simulations of the polarimetric parameters by the T-matrix scattering method are described in Sect. 3. The results of the statistical validation of rainfall estimation are presented in Sect. 4. Finally, the conclusions are given in Sect. 5.

\section{Data and instruments}

\subsection{Disdrometer}

In this study we used the compact 2DVD version deployed on the campus of Kyungpook National University, Daegu, Korea $\left(35.9^{\circ} \mathrm{N}, 128.5^{\circ} \mathrm{E}\right)$. The $2 \mathrm{DVD}$ was installed in an observation field away from the buildings. Disdrometers are used to find the DSD characteristics at a given location. Disdrometer data used in this study were collected by a 2DVD from September 2011 to October 2012.

The 2DVD consists of two orthogonal light sheets (referred to as A and B line-scan cameras). Line-scan cameras have single-line photo detectors. The particle shadows are detected on the photo detectors, and the particle images are recorded from two sides and at different heights when the particles are falling through the measurement area $(10 \mathrm{~cm} \times 10 \mathrm{~cm})$. The 2DVD measures drop size, fall veloc- 
Table 1. Specifications for dual-polarization radar in Bislsan.

\begin{tabular}{ll}
\hline \multicolumn{1}{c}{ Parameters } & Characteristics \\
\hline Variables & $Z_{\mathrm{H}}, V_{r}, \mathrm{SW}, Z_{\mathrm{DR}}, \Phi_{\mathrm{DP}}, K_{\mathrm{DP}}, \rho_{h v}$ \\
Altitude of radar antenna & $1085 \mathrm{~m}$ \\
Transmitter type & $\mathrm{Klystron}$ \\
Transmitter peak power & $750 \mathrm{~kW}$ \\
Antenna diameter & $8.5 \mathrm{~m}$ \\
Beam width of radar & $0.95^{\circ}$ \\
$\quad$ frequency & $2.785 \mathrm{MHz}(\mathrm{S}$-band) \\
range & $150 \mathrm{~km}$ \\
Observation $\quad$ gate size & $125 \mathrm{~m}$ \\
$\quad$ elevations & $-0.5^{\circ}, 0^{\circ}, 0.5^{\circ}, 0.8^{\circ}, 1.2^{\circ}, 1.6^{\circ}$ (6 elevation) \\
\hline
\end{tabular}

ity, and the shape of individual particles. From these data, one can calculate the DSD and all related quantities such as the rain rate, total drop number concentration, and liquid water content. A more detailed description of the 2DVD is given in Kruger and Krajewski (2002).

\subsection{Radar}

The Ministry of Land, Infrastructure, and Transport (MLIT) operates the Bislsan (BSL) dual-polarization radar in Bislsan, Korea $\left(35.7^{\circ} \mathrm{N}, 128.5^{\circ} \mathrm{E}, 1085 \mathrm{~m}\right)$. The BSL S-band radar has observation range of $150 \mathrm{~km}$ and a frequency of $2.5 \mathrm{~min}$ because it is used primarily for hydrological observations and flood forecasts. The BSL S-band radar measures polarimetric variables such as $Z_{\mathrm{H}}, Z_{\mathrm{DR}}, K_{\mathrm{DP}}$, and $\rho_{h v}$ in real time. Six elevation angles from -0.5 to $1.6^{\circ}$ were available, with a gate size resolution of $125 \mathrm{~m}$ and radar beam width of $0.95^{\circ}$. The specifications of the BSL radar are shown in Table 1.

The BSL S-band dual-polarization radar was located about $22.3 \mathrm{~km}\left(17^{\circ}\right)$ away from the 2DVD location (Fig. 1). These geographical locations were adopted to compare the two sets of observation data. We used radar data from September 2011 to October 2012. During this period, rainfall events were analyzed for $Z_{\mathrm{H}}$ and $Z_{\mathrm{DR}}$ calibration and for rainfall estimation. In addition, the $0.0^{\circ}$-elevation plan position indicator (PPI) radar data were used to avoid effects due to beam blocking and ground echoes on the measurements, whilst being as close as possible to the $2 \mathrm{DVD}$. The $Z_{\mathrm{H}}$ and $Z_{\mathrm{DR}}$ radar parameters were averaged over five successive gate size resolutions and two adjacent azimuth angles, and $K_{\text {DP }}$ was calculated from the filtered $\Phi_{\mathrm{DP}}$ as the slope of a least squares fit.

\subsection{Rain gauge}

A tipping bucket rain gauge was used to validate the 2DVD rainfall estimations. The rain gauge used in this study was a RG3-M tipping bucket rain gauge from the Onset Computer Corporation. The maximum rainfall rate of the rain gauge was $127 \mathrm{~mm}$ (5 in) per hour, and the operating tem-

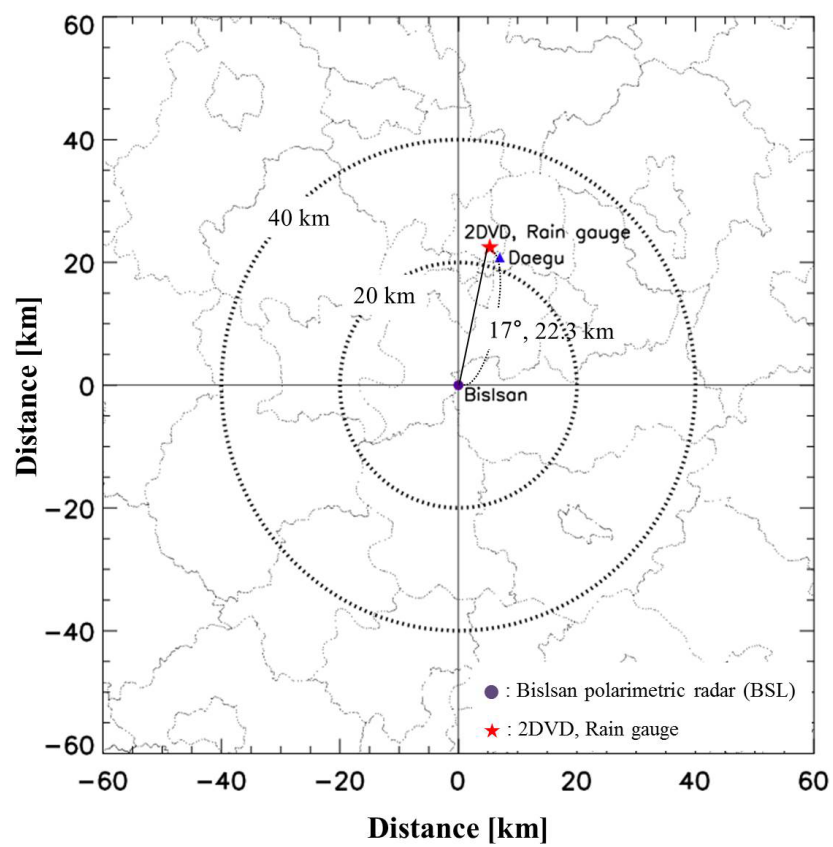

Figure 1. The locations of the Bislsan polarimetric radar and the 2DVD at the rain gauge site.

perature range was from 0 to $50^{\circ} \mathrm{C}$. The bucket size of the rain gauge was $0.2 \mathrm{~mm}$ and the time resolution was $0.5 \mathrm{~s}$. The rain gauge measurements were corrected to reduce instrumental uncertainties through field inter-comparisons with a reference gauge. The rain gauge was installed in the same location as the 2DVD.

\section{Methodology}

\subsection{Quality control of 2DVD data}

The 2DVD observation data were useful for investigating the characteristics of rainfall. However, a number of particle outliers were measured, and these anomalous data points were due to wind turbulence, splashing, break up of drops, and 
mismatching between camera A and B (Raupach and Berne, 2015). These results can lead to incorrect information about the particles. Therefore, before using the 2DVD data, a quality control process was needed.

Figure $2 \mathrm{a}$ and $\mathrm{b}$ show the fall velocity and oblateness distribution according to the raindrop diameter before the data quality control procedure was performed. In Fig. $2 b$ and c, we compare the axis-ratio-diameter relation of Pruppacher and Beard (1970) with that found by the disdrometer before and after the correction, respectively. Some particles had fall velocities beyond the terminal velocity of large raindrops. In particular, the outliers appeared prominently in the small raindrop ranges. To remove these outliers, velocity-based filtering was applied to the 2DVD measurement data (Thurai and Bringi, 2005). The equations used are the following:

$$
\begin{aligned}
& \left|V_{\text {measured }}(D)-V_{\mathrm{A}}(D)\right|<0.4 V_{\mathrm{A}}(D) \\
& V_{\mathrm{A}}(D)=9.65-10.3 \exp (-0.6 D),
\end{aligned}
$$

where $D(\mathrm{~mm})$ is the drop diameter, $V_{\text {measured }}\left(\mathrm{m} \mathrm{s}^{-1}\right)$ is the fall velocity as measured by the $2 \mathrm{DVD}$, and $V_{\mathrm{A}}$ represents the Atlas velocity formula (Atlas et al., 1973). The procedure removed about $17 \%$ of the values that did not correspond well with the expected normal distribution (Fig. 2c). Despite the application of velocity-based filtering, significant bias still remained in the small drop size area. This was due to instrumental limitations such as the mismatch problems with the line-scan cameras and the limited vertical resolution of the instrument. Therefore, the oblateness data corresponding to raindrop diameters smaller than $0.5 \mathrm{~mm}$ were removed when we calculated the new axis-ratio formula.

To analyze the reliability of the 2DVD data, we compared the rain rates calculated from the 2DVD data (Eq. 2) to collocated rain gauge measurements; the difference of accumulated rainfall represents the percent error (Eq. 3).

$$
\begin{aligned}
& R=6 \times 10^{-4} \pi \sum_{D_{\text {min }} \text { max }}^{D} D^{3} V(D) N(D) \Delta D\left[\mathrm{~mm} \mathrm{~h}^{-1}\right] \\
& \mathrm{PE}=\frac{\left|\mathrm{AR}_{\text {rain gauge }}-\mathrm{AR}_{2 \mathrm{DVD}}\right|}{\mathrm{AR}_{\text {rain gauge }}} \times 100[\%]
\end{aligned}
$$

Here, $D_{\max }$ and $D_{\min }$ are the maximum and minimum diameters of the observed drops in mm, $N(D)$ is the drop number concentration in $\mathrm{mm}^{-1} \mathrm{~m}^{-3}, V(D)$ is the drop fall velocity in $\mathrm{m} \mathrm{s}^{-1}$, and $D$ is the drop interval $(D=0.2 \mathrm{~mm})$. The drop fall velocity formula used was that derived by Atlas et al. (1973); $\mathrm{PE}$ is the percent error and AR is the accumulated rainfall in $\mathrm{mm}$.

We analyzed the rainfall cases that occurred from September 2011 to October 2012. Figure 3 shows the accumulated rainfall computed from the $2 \mathrm{DVD}$ and rain gauge data for six of these cases. The six events occurred at (i) 00:0009:00 UTC on 14 October 2011 (Fig. 3a), (ii) 14:0023:59 UTC on 2 April 2012 (Fig. 3b), (iii) 00:00-23:59 UTC on 21 April 2012 (Fig. 3c), (iv) 00:00-08:00 UTC on 25
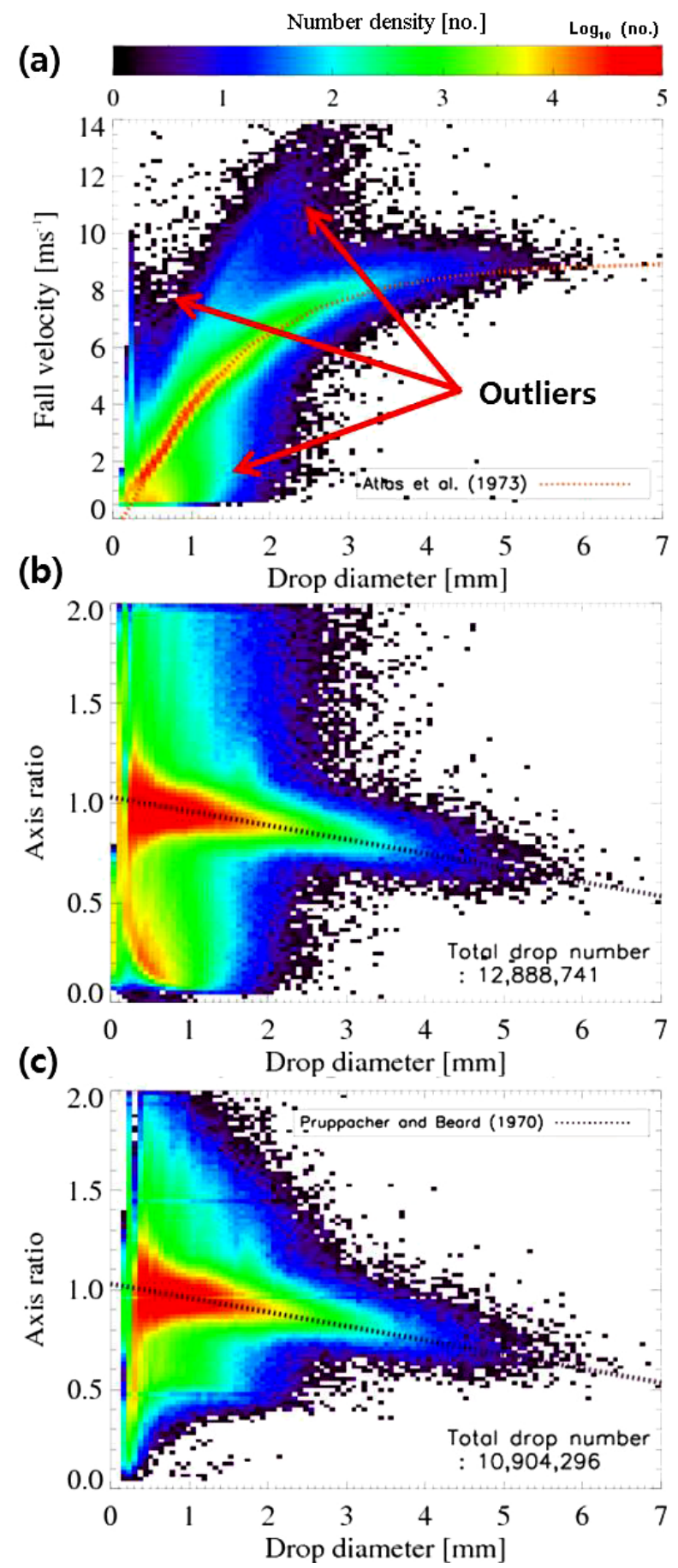

Figure 2. Distribution of fall velocity and oblateness according to drop diameter. (a) Velocity-based filter for the drop measurements. The color scale represents the drop number density (log scale). The dotted line (orange) represents the results from the velocity formula of Atlas et al. (1973). (b) Drop axis ratios for all measured drops. (c) Drop axis ratios after removing mismatched drops. The dotted line (black) represents the mean axis-ratio results from the formula given in Pruppacher and Beard (1970). 
(a)

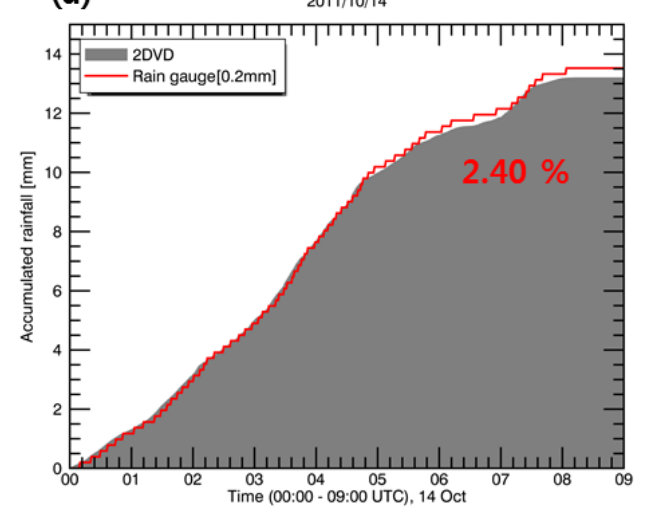

(c)

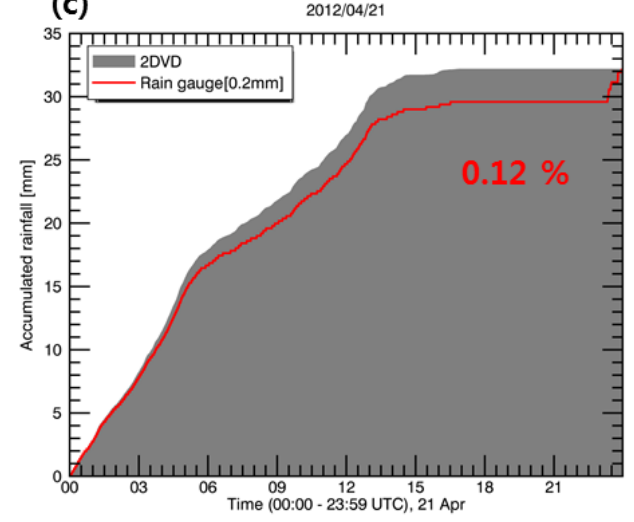

(e)

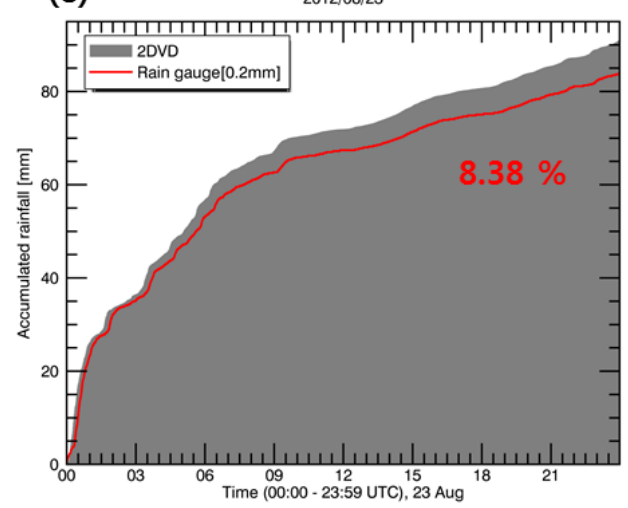

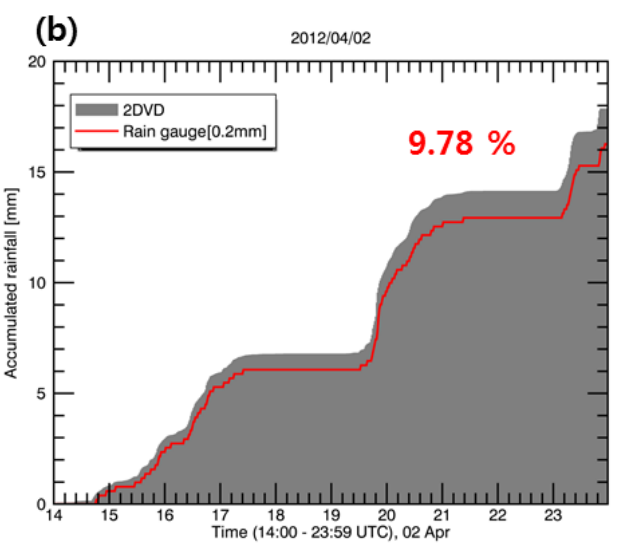

(d)
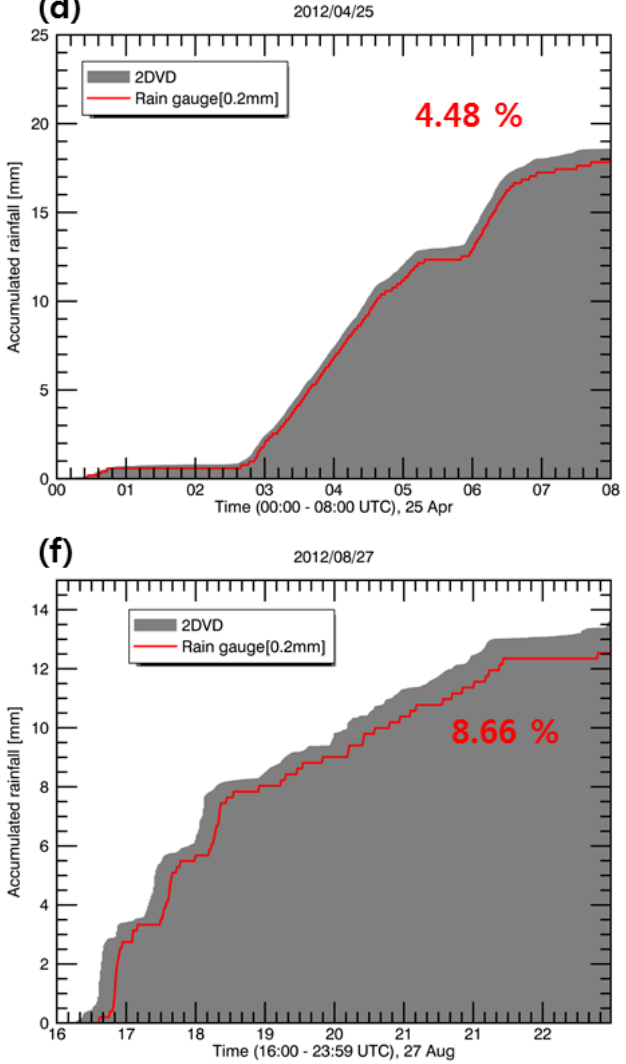

Figure 3. Time series of accumulated rainfall measured from the rain gauge and estimated from the 2DVD: (a) 14 October 2011, (b) 2 April 2012, (c) 21 April 2012, (d) 25 April 2012. (e) 23 August 2012, and (f) 27 August 2012.

April 2012 (Fig. 3d), (v) 00:00-23:59 UTC on 23 August 2012 (Fig. 3e), and (vi) 16:00-23:59 UTC on 27 August 2012 (Fig. 3f). Figure $3 \mathrm{a}$ shows the accumulated rainfall computed from the 2DVD and rain gauge data on 14 October 2011. As shown in Figs. 3a-f, the percent errors from the six considered rainfall cases were $2.40,9.78,0.12,4.48,8.38$ and $8.66 \%$, respectively. The overall distribution between the 2DVD and rain gauge results was good. In general, earlier studies have found that rainfall differences between disdrometer and rain gauge data were mostly in the range of 10 to $20 \%$ (McFarquhar and List, 1993; Sheppard and Joe,
1994; Hagen and Yuter, 2003; Tokay et al., 2003). These differences might have been due to such issues as differences in instruments, effects due to the measurement environment, and rainfall variability. Therefore, the rainfall differences between the 2DVD and rain gauge results used in this study were limited to a maximum of $20 \%$ error, and the 2DVD data were excluded from the analysis when the rainfall difference between the 2DVD and rain gauge results exceeded $20 \%$.

After the quality control process, 33 rainfall cases were selected for further investigations of the characteristics of 
Table 2. Summary of the date, type of precipitation, and accumulated rainfall comparison values between 2DVD and rain gauge measurements for the 33 rainfall events.

\begin{tabular}{|c|c|c|c|c|c|}
\hline \multirow[t]{2}{*}{ Date } & \multirow{2}{*}{$\begin{array}{c}\text { Time of } \\
\text { of observation (UTC) }\end{array}$} & \multirow[b]{2}{*}{ Type } & \multicolumn{2}{|c|}{ Accumulated rainfall (mm) } & \multirow[t]{2}{*}{ PE $(\%)$} \\
\hline & & & 2DVD & rain gauge & \\
\hline $09 / 05 / 11$ & $01: 00-15: 00$ & $\mathrm{C}$ & 7.07 & 6.86 & 3.16 \\
\hline 09/09/11 & $15: 20-21: 20$ & $\mathrm{~S}$ & 4.28 & 4.31 & 0.72 \\
\hline 09/10/11 & $00: 00-23: 59$ & $\mathrm{C}$ & 19.48 & 17.83 & 9.28 \\
\hline $09 / 29 / 11$ & 00:00-17:00 & $\mathrm{S}$ & 3.81 & 3.72 & 2.46 \\
\hline $10 / 13 / 11$ & 00:00-23:59 & S & 3.93 & 4.11 & 4.59 \\
\hline $10 / 14 / 11$ & 00:00-09:00 & $S$ & 13.20 & 13.52 & 2.40 \\
\hline $10 / 21 / 11$ & $06: 00-23: 59$ & $S$ & 53.33 & 65.83 & 18.99 \\
\hline $04 / 02 / 12$ & $14: 00-23: 59$ & M & 17.85 & 16.26 & 9.78 \\
\hline $04 / 21 / 12$ & 00:00-23:59 & $\mathrm{S}$ & 32.17 & 32.13 & 0.12 \\
\hline $04 / 25 / 12$ & 00:00-08:00 & $S$ & 18.63 & 17.83 & 4.48 \\
\hline $05 / 01 / 12$ & 08:00-21:00 & $S$ & 4.08 & 3.53 & 15.62 \\
\hline $05 / 08 / 12$ & 07:00-11:00 & $\mathrm{C}$ & 8.94 & 9.60 & 6.89 \\
\hline $05 / 14 / 12$ & $00: 00-15: 00$ & $\mathrm{~S}$ & 22.16 & 19.79 & 10.88 \\
\hline $05 / 28 / 12$ & 06:00-07:00 & $\mathrm{C}$ & 15.19 & 14.50 & 4.79 \\
\hline 06/08/12 & $03: 00-23: 59$ & $\mathrm{C}$ & 17.07 & 19.40 & 11.98 \\
\hline $06 / 23 / 12$ & 00:00-08:00 & $\mathrm{C}$ & 13.43 & 14.50 & 4.79 \\
\hline 07/06/12 & 00:00-18:00 & $\mathrm{C}$ & 22.43 & 20.18 & 11.13 \\
\hline $07 / 12 / 12$ & $17: 00-21: 00$ & M & 7.51 & 7.45 & 0.88 \\
\hline 07/13/12 & 01:00-12:00 & $\mathrm{C}$ & 25.22 & 25.08 & 0.55 \\
\hline $07 / 15 / 12$ & 00:00-12:00 & $\mathrm{C}$ & 8.22 & 7.64 & 7.54 \\
\hline 07/16/12 & $15: 00-23: 59$ & M & 16.40 & 18.42 & 10.97 \\
\hline $07 / 21 / 12$ & 09:00-10:30 & $\mathrm{C}$ & 5.86 & 5.68 & 3.15 \\
\hline 08/12/12 & 01:00-18:00 & $\mathrm{C}$ & 20.25 & 18.42 & 9.95 \\
\hline 08/13/12 & $00: 00-15: 00$ & $\mathrm{C}$ & 37.27 & 34.09 & 9.31 \\
\hline 08/23/12 & 00:00-23:59 & M & 90.88 & 83.86 & 8.38 \\
\hline 08/24/12 & $00: 00-23: 59$ & $\mathrm{~S}$ & 7.37 & 7.45 & 1.01 \\
\hline 08/27/12 & $16: 00-23: 59$ & S & 13.62 & 12.54 & 8.66 \\
\hline 08/29/12 & $19: 00-23: 59$ & S & 6.26 & 5.29 & 18.39 \\
\hline 09/09/12 & 00:00-23:59 & S & 21.56 & 18.65 & 15.61 \\
\hline 09/16/12 & 00:00-23:59 & S & 83.12 & 69.88 & 18.95 \\
\hline $09 / 17 / 12$ & 00:00-07:00 & M & 63.64 & 58.55 & 8.69 \\
\hline $10 / 22 / 12$ & 06:00-11:00 & M & 13.63 & 14.92 & 8.64 \\
\hline $10 / 27 / 12$ & 00:00-09:00 & $\mathrm{S}$ & 8.77 & 8.20 & 6.94 \\
\hline
\end{tabular}

rainfall over the Korean Peninsula. The accuracy of the 33 rainfall cases was in the range of $0.12-18.99 \%$ compared to in situ rain gauge data. The radar reflectivity and $1 \mathrm{~h}$ rainfall rates measured by the rain gauge were used to classify the data into different precipitation types. The criterion for the reflectivity described by Chang et al. (2009) was applied in the present study, and rainfall rates that had values of $R>5 \mathrm{~mm} \mathrm{~h}^{-1}\left(\leq 5 \mathrm{~mm} \mathrm{~h}^{-1}\right)$ were considered to be of the convective (stratiform) type. The data set consisted of 15 stratiform rainfall cases, 12 convective rainfall cases, and 6 mixed rainfall cases (total of 33 rainfall events) with 17618 min DSD samples. The precipitation type, rainfall difference, and accumulated rainfall for the 2DVD and rain gauge results are listed in Table 2. Figure 4 shows the hourly and total accumulated rainfall for the 2DVD and rain gauge results. The overall agreement between the 2DVD and the rain gauge results was good, and the total accumulated rain- fall recorded by the rain gauge was greater than that of the 2DVD by about $0.30 \%$.

\subsection{Raindrop axis ratio}

A very small raindrop has an approximately spherical shape that becomes oblate as its size increases. The shape of a raindrop according to the drop size can be expressed as the mean axis-ratio relation. The mean raindrop shape is associated with the measured DSD shape and diameter, which is related to the variation of DSD. The DSD variations depend on different storm types and climatic regimes (Marzuki et $\mathrm{al}, 2013$ ), and they affects rainfall rates derived from polarimetric radar measurements of reflectivity. Hence, in order to produce rainfall estimation algorithms reflective of the rainfall characteristic of the Korean Peninsula, a new mean axisratio relation, using the 2DVD data listed in Table 2, was de- 

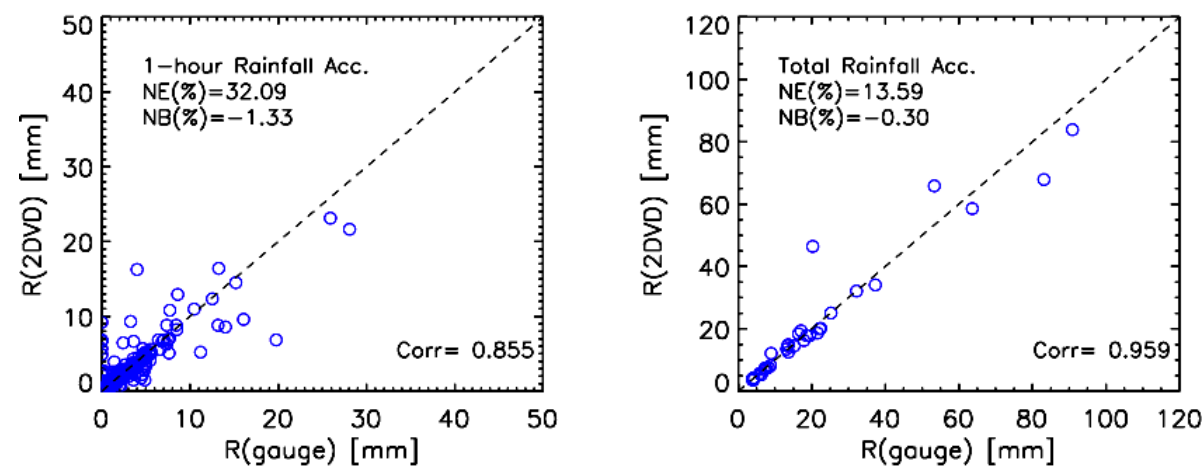

Figure 4. One-hour (left panel) and total accumulated rainfall (right panel) from the 2DVD and rain gauge for the 33 rainfall cases.

rived as a polynomial function. The size of the diameter bin was $0.2 \mathrm{~mm}$, and the oblateness data corresponding to raindrop diameters smaller than $0.5 \mathrm{~mm}$ were removed when we derived the new axis-ratio relation because oblateness in the small range $(D<0.5 \mathrm{~mm})$ was significantly influenced by the calibration of the instrument (Marzuki et al., 2013). In addition, we only displayed the average values for the bins containing more than five drops in order to have sufficient numbers of raindrops. Therefore, the measured maximum diameter could reach to about $8 \mathrm{~mm}$; however, the mean axis-ratio fitting was established to be within $7 \mathrm{~mm}$ diameter because it does not have a sufficient number of values in more than $7 \mathrm{~mm}$ diameter.

In order to produce the mean axis-ratio relation, various fitting methods such as linear and polynomial (second-, third, fourth-order) fits were tried. The third-order polynomial relation was deemed the most suitable for the observation data, as this, relation performed (i.e., goodness of the fitting) better than others. The third-order polynomial new mean axis-ratio relation $(b / a)$ is as shown in Eq. (4), which can be reasonably extended to $7 \mathrm{~mm}$ :

$$
\begin{aligned}
b / a & =0.997845-0.0208475 D-0.0101085 D^{2} \\
& +6.4332 \times 10^{-4} D^{3}(0.5 \leq D \leq 7 \mathrm{~mm}),
\end{aligned}
$$

where $a$ and $b$ are the major and minor axis, respectively, and $D$ is the equivalent volume diameter of the particle in $\mathrm{mm}$. The statistical measures corresponding to the correlation coefficient, root-mean-square error (RMSE), and mean absolute error (MAE) were 0.989, 0.025, and 0.012, respectively.

\subsection{Disdrometer-rainfall algorithms}

In order to produce the polarimetric rainfall algorithms, the theoretical polarimetric variables (e.g., $Z_{\mathrm{H}}, Z_{\mathrm{DR}}$, and $K_{\mathrm{DP}}$ ) were simulated from the 2DVD data by using the T-matrix (transition) method (Zhang et al., 2001). The polarimetric variables depend on the shape of raindrops. The polarimetric rainfall algorithms were derived by making assumptions about different axis-ratio relations. First, we calculated the complex scattering amplitudes of raindrops at the S-band of the $10.7 \mathrm{~cm}$ wavelength by using the mean axis-ratio relations. Second, we calculated the scattering amplitudes for the different axis-ratio relations that were used for the production of the polarimetric variables. The dual-polarimetric variables were calculated by using Eqs. (5-7) (Jung et al., 2010):

$$
\begin{aligned}
Z_{h} & =\frac{4 \lambda^{4}}{\pi^{4}\left|K_{\mathrm{w}}\right|^{2}} \int_{0}^{D_{\max , x}} A\left|f_{\mathrm{a}}(\pi)\right|^{2}+B\left|f_{\mathrm{b}}(\pi)\right|^{2} \\
& +2 C R_{\mathrm{e}}\left[f_{\mathrm{a}}(\pi) f_{\mathrm{b}}{ }^{*}(\pi)\right] N(D) \mathrm{d} D\left[\mathrm{~mm}^{6} \mathrm{~m}^{-3}\right],
\end{aligned}
$$

$$
\begin{aligned}
Z_{v} & =\frac{4 \lambda^{4}}{\pi^{4}\left|K_{\mathrm{w}}\right|^{2}} \int_{0}^{D_{\max , x}} B\left|f_{\mathrm{a}}(\pi)\right|^{2}+A\left|f_{\mathrm{b}}(\pi)\right|^{2} \\
& +2 C R_{\mathrm{e}}\left[f_{\mathrm{a}}(\pi) f_{\mathrm{b}}{ }^{*}(\pi)\right] N(D) \mathrm{d} D\left[\mathrm{~mm}^{6} \mathrm{~m}^{-3}\right],
\end{aligned}
$$

where

$$
\begin{aligned}
& A=<\cos ^{4} \Phi>=\frac{1}{8}\left(3+4 \cos 2 \bar{\phi} e^{-2 \sigma^{2}}+\cos 4 \bar{\phi} e^{-8 \sigma^{2}}\right) \\
& B=<\sin ^{4} \Phi>=\frac{1}{8}\left(3-4 \cos 2 \bar{\phi} e^{-2 \sigma^{2}}+\cos 4 \bar{\phi} e^{-8 \sigma^{2}}\right)
\end{aligned}
$$

and

$$
\begin{aligned}
& C=<\sin ^{2} \Phi \cos ^{2} \Phi>=\frac{1}{8}\left(1-\cos 4 \bar{\phi} e^{-8 \sigma^{2}}\right) \\
& K_{\mathrm{DP}}=\frac{180 \lambda}{\pi} \int_{0}^{D_{\max }} C_{\mathrm{k}} R_{\mathrm{e}}\left[f_{\mathrm{a}}(0)-f_{\mathrm{b}}(0)\right] N(D) \mathrm{d} D\left[{ }^{\circ} \mathrm{km}^{-1}\right] .
\end{aligned}
$$

Here, $C_{\mathrm{k}}=<\cos 2 \Phi>=\cos 2 \Phi e^{-2 \sigma^{2}}$.

$f_{\mathrm{a}}(0)$ and $f_{\mathrm{b}}(0)$ are complex forward-scattering amplitudes and $f_{\mathrm{a}}(\pi)$ and $f_{\mathrm{b}}(\pi)$ are complex backscattering amplitudes for polarization along the major and minor axes, respectively. Additionally, $f_{\mathrm{a}}{ }^{*}$ and $f_{\mathrm{b}}{ }^{*}$ are their respective conjugates, $\bar{\phi}$ is the mean canting angle, and $\sigma$ is the standard deviation of the canting angle. The terms $\bar{\phi}$ and $\sigma$ were assumed to be 0 and $7^{\circ}$, respectively (Huang et al., 2008). The 
Table 3. List of different polarimetric rainfall relations used for rainfall estimations and the mean absolute error (MAE), root-mean-square error (RMSE), and correlation coefficient for estimated rain rates vs. observations.

\begin{tabular}{|c|c|c|c|c|c|c|c|}
\hline \multicolumn{8}{|c|}{$R\left(Z_{h}\right)=\alpha\left|Z_{h}\right|^{\beta}$} \\
\hline & \multicolumn{3}{|c|}{ Polarimetric rainfall relation } & \multicolumn{3}{|c|}{ Scatterplot $R-R_{\mathrm{e}}$} & \multirow[t]{2}{*}{ Assumptions } \\
\hline & \multicolumn{3}{|c|}{$\beta$} & \multirow{2}{*}{$\begin{array}{c}\text { MAE } \\
0.96\end{array}$} & \multirow{2}{*}{$\begin{array}{c}\text { RMSE } \\
2.40\end{array}$} & Corr. & \\
\hline 1 & 0.0568 & 0.5876 & & & & 0.93 & Pruppacher and Beard (1970) \\
\hline 2 & 0.0587 & 0.5849 & & 0.97 & 2.42 & 0.92 & Beard and Chuang (1987) \\
\hline 3 & 0.0588 & 0.5851 & & 0.97 & 2.42 & 0.92 & Brandes et al. (2002) \\
\hline 4 & 0.0575 & 0.5870 & & 0.97 & 2.41 & 0.92 & New axis ratio (experimental fit) \\
\hline \multicolumn{8}{|c|}{$R\left(K_{\mathrm{DP}}\right)=\alpha\left|K_{\mathrm{DP}}\right|^{\beta}$} \\
\hline & \multicolumn{3}{|c|}{ Polarimetric rainfall relation } & \multicolumn{3}{|c|}{ Scatterplot $R-R_{\mathrm{e}}$} & \multirow[t]{2}{*}{ Assumptions } \\
\hline & $\alpha$ & $\beta$ & & MAE & RMSE & Corr. & \\
\hline 1 & 38.59 & 0.834 & & 0.47 & 1.05 & 0.99 & Pruppacher and Beard (1970) \\
\hline 2 & 43.66 & 0.765 & & 0.67 & 1.43 & 0.97 & Beard and Chuang (1987) \\
\hline 3 & 46.85 & 0.740 & & 0.82 & 1.64 & 0.97 & Brandes et al. (2002) \\
\hline 4 & 42.20 & 0.831 & & 0.46 & 1.15 & 0.98 & New axis ratio (experimental fit) \\
\hline \multicolumn{8}{|c|}{$R\left(Z_{h}, Z_{\mathrm{DR}}\right)=\alpha Z_{h}^{\beta} 10^{0.1 \gamma Z_{\mathrm{DR}}}$} \\
\hline & \multicolumn{3}{|c|}{ Polarimetric rainfall relation } & \multicolumn{3}{|c|}{ Scatterplot $R-R_{\mathrm{e}}$} & Assumptions \\
\hline & $\alpha$ & $\beta$ & $\gamma$ & MAE & RMSE & Corr. & \\
\hline 1 & 0.0112 & 0.89 & -4.0964 & 0.45 & 0.77 & 0.99 & Pruppacher and Beard (1970) \\
\hline 2 & 0.0094 & 0.88 & -3.5321 & 0.46 & 0.84 & 0.99 & Beard and Chuang (1987) \\
\hline 3 & 0.0090 & 0.88 & -3.4908 & 0.47 & 0.86 & 0.99 & Brandes et al. (2002) \\
\hline 4 & 0.0114 & 0.87 & -3.7750 & 0.48 & 0.90 & 0.99 & New axis ratio (experimental fit) \\
\hline \multicolumn{8}{|c|}{$R\left(K_{\mathrm{DP}}, Z_{\mathrm{DR}}\right)=\alpha K_{\mathrm{DP}}^{\beta} 10^{0.1 \gamma Z_{\mathrm{DR}}}$} \\
\hline & \multicolumn{3}{|c|}{ Polarimetric rainfall relation } & \multicolumn{3}{|c|}{ Scatterplot $R-R_{\mathrm{e}}$} & Assumptions \\
\hline & $\alpha$ & $\beta$ & $\gamma$ & MAE & RMSE & Corr. & \\
\hline 1 & 66.56 & 0.96 & -1.4041 & 0.29 & 0.45 & 1.00 & Pruppacher and Beard (1970) \\
\hline 2 & 84.02 & 0.93 & -1.6854 & 0.44 & 0.66 & 1.00 & Beard and Chuang (1987) \\
\hline 3 & 96.57 & 0.92 & -1.9085 & 0.59 & 0.86 & 0.99 & Brandes et al. (2002) \\
\hline 4 & 74.80 & 0.97 & -1.5489 & 0.23 & 0.36 & 1.00 & New axis ratio (experimental fit) \\
\hline
\end{tabular}

maximum size of the observed particles is $D_{\max }=8 \mathrm{~mm}$, the radar wavelength is $\lambda=10.7 \mathrm{~cm}$ (S-band), the dielectric factor for water is $K_{\mathrm{w}}=0.93$, and $N(D)$ was calculated by using the 2DVD measurements.

Polarimetric rainfall relations between $R$ and dualpolarimetric variables were derived when the rain rate was greater than $0.1 \mathrm{~mm} \mathrm{~h}^{-1}$. The derived new polarimetric rainfall relations according to different axis-ratio relations are presented in Table 3.

\subsection{Calibration of the radar}

The radar measurements are affected by various observational errors, such as ground echoes, beam broadening, anomalous propagation echoes, and calibration biases of $\operatorname{radar} Z_{\mathrm{H}}$ and $Z_{\mathrm{DR}}$. These errors can lead to significant un- certainty in precipitation estimations. Therefore, accommodation of the calibration bias of radar is necessary to improve quantitative rainfall estimations involving $Z_{\mathrm{H}}$ and/or $Z_{\mathrm{DR}}$. The radar calibration was done for light rainfall events, and the simulated theoretical $Z_{\mathrm{H}}$ and $Z_{\mathrm{DR}}$ variables based on the new axis-ratio relation (Eq. 4) were used.

The calibration biases of $Z_{\mathrm{H}}$ and $Z_{\mathrm{DR}}$ were calculated from the comparison of measured $Z_{\mathrm{H}}$ and $Z_{\mathrm{DR}}$ with the simulated $Z_{\mathrm{H}}$ and $Z_{\mathrm{DR}}$ from the $2 \mathrm{DVD}$ measurements. To compare polarimetric radar parameters, the cross-match point must first be determined. This is because 2DVD data consist of point measurements, whereas radar data are measured in a sampling volume. The BSL S-band radar data were averaged over five successive gates and two adjacent azimuth angles centered on the 2DVD location. The elevation angle of $0.0^{\circ}$ PPI was used. The radar rainfall estimation reliabil- 


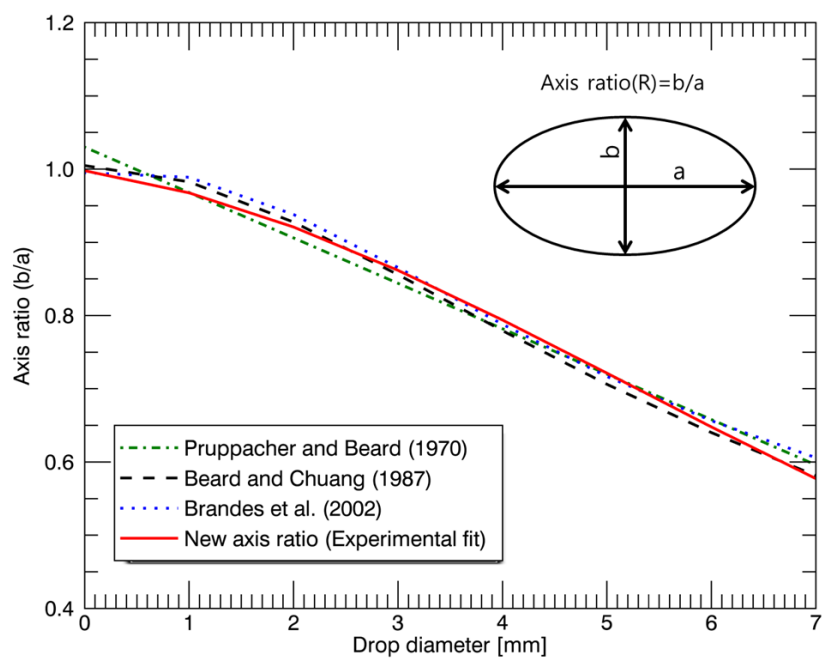

Figure 5. Different raindrop axis-ratio relations for the oblate raindrop model. The upper right subfigure illustrates the axis ratio of an oblate raindrop.

ity was assessed before and after the calibration to test the effectiveness of the calibration process.

\section{Results}

\subsection{Comparison of raindrop axis-ratio relations}

We compared the new axis-ratio experimental fit with existing mean axis-ratio relations such as those of Pruppacher and Beard (1970), Beard and Chuang (1987), and Brandes et al. (2002) (see Fig. 5). Consisting in the following polynomial formulas:

$b / a=1.03-0.062 D(1 \leq D \leq 9 \mathrm{~mm})$

$b / a=1.0048+5.7 \times 10^{-4} D-2.628 \times 10^{-2} D^{2}$

$+3.682 \times 10^{-3} D^{3}-1.677 \times 10^{-4} D^{4}(1 \leq D \leq 7 \mathrm{~mm})$

$b / a=0.9951+0.02510 D-0.03644 D^{2}$

$+5.303 \times 10^{-3} D^{3}-2.492 \times 10^{-4} D^{4}(1 \leq D \leq 8 \mathrm{~mm})$.

Equation (8) from Pruppacher and Beard (1970) is a linear relation derived by measurements in a wind tunnel. Equation (9) is a fourth-order polynomial formula from a numerical model. Equation (10) is a polynomial empirical relation developed by Brandes et al. (2002) that was derived by combining drop shape observations. The Pruppacher and Beard (1970) linear relation results (Eq. 8, green dash-dot line) fell below the new mean axis-ratio for $1 \leq D<5 \mathrm{~mm}$. The Beard and Chuang (1987) polynomial relation results (Eq. 9, black dashed line) ranged from 2.5 to $6.5 \mathrm{~mm}$ lower than the new mean axis-ratio relation values. The new mean axis-ratio fit was more oblate than that obtained with the Brandes et al. (2002) polynomial empirical relation (Eq. 10, blue dotted line) when the raindrop sizes were greater than
$5.5 \mathrm{~mm}$ and less than $2.5 \mathrm{~mm}$. With the exception of this case, the new axis ratio yielded results similar to those from Eq. (10) for diameters ranging from 3 to $5.5 \mathrm{~mm}$. The new mean axis-ratio relation was very similar to existing axisratio relations except for small particles $(\leq 2 \mathrm{~mm})$ and large particles $(\geq 5.5 \mathrm{~mm})$.

The differences in the mean axis-ratio relations seemed small, and dependence of the raindrop axis ratio on climatic regimes was not clearly observed, although raindrop shapes can be influenced by the temperature and pressure (Beard and Chuang, 1987). Differences of raindrop shape can also be caused by measurement errors, drop oscillation, event selection criterion, and the fitting method used (Thurai and Bringi, 2005). A small error in the mean axis ratio can lead to significant errors in the estimated DSD and rainfall rates (Bringi and Chandrasekar, 2001). Therefore, the consideration of the accurate raindrop shapes based on long-term DSD data is necessary to improve the polarimetric rainfall estimations.

\subsection{Verification of polarimetric rainfall algorithms}

\subsubsection{Variability of DSD in rainfall estimations}

To investigate the variability of the DSD in rainfall estimations from polarimetric parameters, the rain rate $R_{\mathrm{e}}$ was estimated by utilizing various combinations of polarimetric variables and then was compared with $\mathrm{R}$ derived from the 2DVD results (Eq. 2). The MAE, RMSE, and correlation coefficient (Corr.) were calculated according to the following equations:

$$
\begin{aligned}
& \text { MAE }=\frac{1}{N} \sum\left|R-R_{\mathrm{e}}\right|\left[\mathrm{mm} \mathrm{h}^{-1}\right] \\
& \text { RMSE }=\left(\frac{1}{N} \sum\left(R-R_{\mathrm{e}}\right)^{2}\right)^{0.5}\left[\mathrm{~mm} \mathrm{~h}^{-1}\right] \\
& \text { Corr. }=\frac{1}{N-1} \frac{\sum\left[(R-\bar{R})\left(R_{\mathrm{e}}-\bar{R}_{\mathrm{e}}\right)\right]}{\sqrt{\operatorname{Var}(R) \operatorname{Var}\left(R_{\mathrm{e}}\right)}},
\end{aligned}
$$

where $R$ is the rain rate from observed 1-min DSDs and $R_{\mathrm{e}}$ is the rain rate from various polarimetric rainfall algorithms. $R_{\mathrm{e}}$ can then be obtained from the 2DVD data. The $N$ is the number of comparisons. Figure 6 shows the scatterplot of $R$ and $R_{\mathrm{e}}$ for polarimetric rainfall algorithms based on the new axis-ratio relation. The scatter indicates the effect of DSD variability on rain estimations. The comparison between rain rates from the observed $\mathrm{R}$ and those estimated from $R_{\mathrm{e}}$ showed good overall agreement. In particular, the statistics for the scatter showed the best results (MAE $=0.23 \mathrm{~mm} \mathrm{~h}^{-1}$, RMSE $=0.36 \mathrm{~mm} \mathrm{~h}^{-1}$, and Corr. $=1.00$ ) when using the $R\left(K_{\mathrm{DP}}, Z_{\mathrm{DR}}\right)$ based on the new axis-ratio relation. The use of the single parameter $R\left(Z_{\mathrm{H}}\right)$ resulted in an increase of the MAE $\left(0.97 \mathrm{~mm} \mathrm{~h}^{-1}\right)$ and RMSE $\left(2.41 \mathrm{~mm} \mathrm{~h}^{-1}\right)$, but in a decrease of the Corr. (0.93) compared to the other polarimetric rainfall relations. Other polarimetric rainfall algorithms based on existing axis-ratio relations (Eqs. 8-10) showed similar results. A summary of the statistics according to polarimetric rainfall algorithms and mean axis-ratio relations 

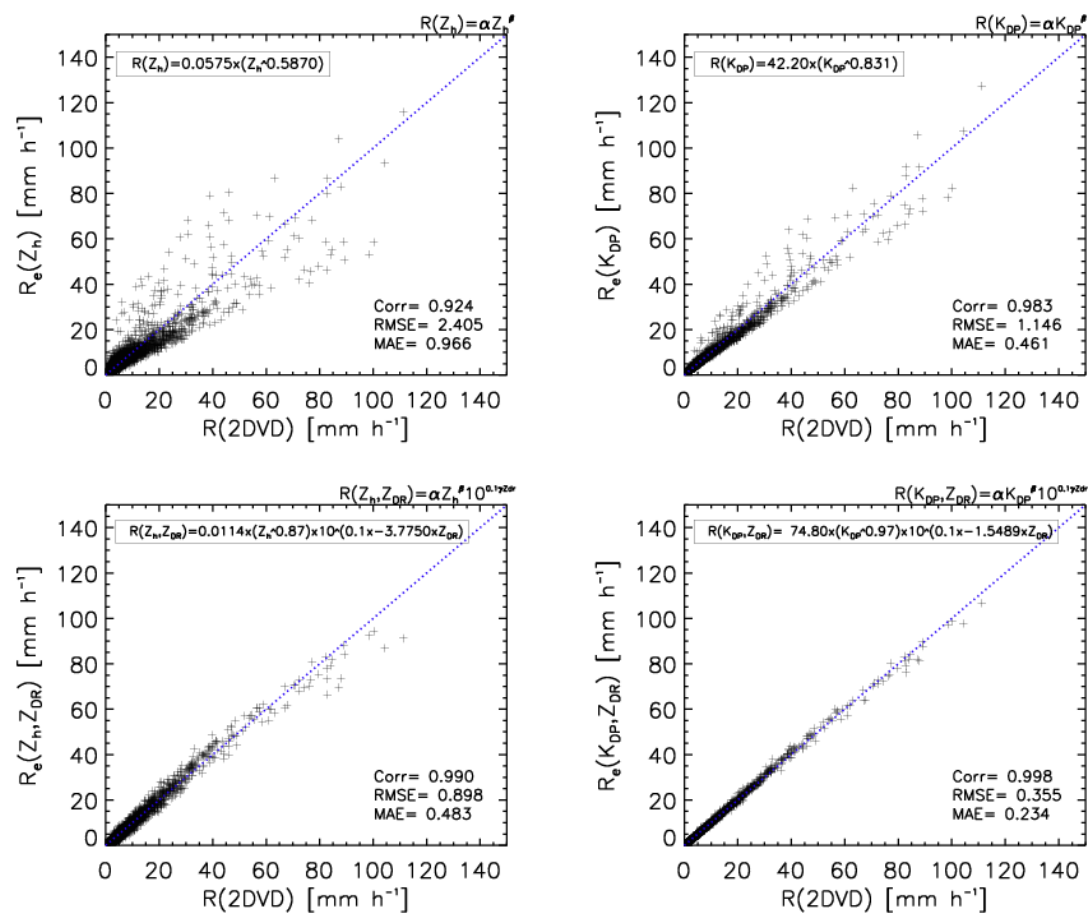

Figure 6. Scatterplot of $R$ derived from observed DSDs (17 618 min samples) and $R_{\mathrm{e}}$ estimated from combinations of polarimetric parameters. $R_{\mathrm{e}}$ was then obtained from the same data set.

are presented in Table 3 . The differences in performance between the dual-polarization rainfall algorithms under practical conditions can also be due to the different error structures of dual-polarization measurements.

The reflectivity factor is affected by the absolute calibration error, and it requires accurate knowledge of the radar constant. The differential reflectivity is a relative power measurement of any rainfall algorithm. Therefore, it can be measured without being affected by absolute calibration errors. However, the $Z_{\mathrm{DR}}$-based algorithm needs to be used in conjunction with $Z_{h}$ or $K_{\mathrm{DP}}$ because $Z_{\mathrm{DR}}$ is a relative power measurement of any rainfall algorithm. Unlike $Z_{h}$ and $Z_{\mathrm{DR}}$, $K_{\mathrm{DP}}$ is independent of the absolute calibration error attenuation because it is related to the phase shift of the electromagnetic wave. However, $K_{\mathrm{DP}}$ is relatively noisy in light rain (a low rain rate). Thus, the advantages and disadvantages of each polarimetric variable translate into the error of rainfall algorithms (Bringi and Chandrasekar, 2001).

\subsubsection{Validation of rainfall estimation algorithms}

In order to evaluate radar rainfall estimations according to different rainfall relations and raindrop shapes, we compared the $1 \mathrm{~h}$ rain rate from the BSL S-band radar with the hourly rain rate obtained by the use of the rain gauge in Daegu, Korea. Furthermore, the rainfall estimate from the 2DVD data was included for comparison. Here, the time of observations was short and unstable rainfall events in regard to the conti- nuity and stability of measurement data were excluded from the analysis. Therefore, Statistical validation of the radar and 2DVD rainfall estimates for the different rainfall relations were performed for 18 rainfall events among the 33 rainfall cases. The MAE and RMSE are given by

$$
\begin{aligned}
& \text { MAE }=\frac{1}{N} \sum\left|R_{\mathrm{R}}-R_{\mathrm{G}}\right|\left[\mathrm{mm} \mathrm{h}^{-1}\right] \\
& \text { RMSE }=\left(\frac{1}{N} \sum\left(R_{\mathrm{R}}-R_{\mathrm{G}}\right)^{2}\right)^{0.5}\left[\mathrm{~mm} \mathrm{~h}^{-1}\right],
\end{aligned}
$$

where $R_{\mathrm{R}}$ is obtained by the radar (or 2DVD) averaged $1 \mathrm{~h}$ rain rate $\left(\mathrm{mm} \mathrm{h}^{-1}\right)$, and $R_{\mathrm{G}}$ is measured by the rain gauge averaged $1 \mathrm{~h}$ rain rate $\left(\mathrm{mm} \mathrm{h}^{-1}\right)$. The results are presented in Table 4. According to the DSD statistics, the combined polarimetric rainfall relations using $Z_{\mathrm{DR}}$ and $K_{\mathrm{DP}}$ were more efficient than the single-parameter rainfall relation for estimated 2DVD rainfall. In particular, when using the new axisratio relation, the $R\left(K_{\mathrm{DP}}, Z_{\mathrm{DR}}\right)$ relation performed better than the others. These results can be found in Fig. 7, which shows a scatterplot of the $1 \mathrm{~h}$ rain rate from the rain gauge and the radar (or 2DVD) data developed by using the new mean axis-ratio relation for 18 rainfall events. The pluses represent $1 \mathrm{~h}$ gauge rain rates vs. radar rain rates from different rainfall relations and the squares indicate gauge vs. 2DVD rain rates. In the single rainfall relation with $Z_{h}$ (Fig. 7a), some amount of scatter was present (MAE $=0.96 \mathrm{~mm} \mathrm{~h}^{-1}$ and $\mathrm{RMSE}=1.24 \mathrm{~mm} \mathrm{~h}^{-1}$ ), and the scatter decrease 
Table 4. Mean absolute error (MAE) and root-mean-square error (RMSE) of the radar estimates of hourly rain rates for the different radar rainfall algorithms listed in Table 3.

\begin{tabular}{|c|c|c|c|c|c|}
\hline \multicolumn{6}{|c|}{$R\left(Z_{\mathrm{H}}\right)=\alpha \mid Z_{\mathrm{H}^{\mid}}^{\beta}$} \\
\hline & \multicolumn{2}{|c|}{ MAE } & \multicolumn{2}{|c|}{ RMSE } & \multirow[t]{2}{*}{ Assumptions } \\
\hline & RADAR & 2DVD & RADAR & 2DVD & \\
\hline 1 & 1.02 & 0.96 & 1.39 & 1.24 & Pruppacher and Beard (1970) \\
\hline 2 & 1.03 & 0.96 & 1.39 & 1.25 & Beard and Chuang (1987) \\
\hline 3 & 1.03 & 0.96 & 1.39 & 1.25 & Brandes et al. (2002) \\
\hline 4 & 1.02 & 0.96 & 1.39 & 1.24 & New axis ratio (experimental fit) \\
\hline \multicolumn{6}{|c|}{$R\left(K_{\mathrm{DP}}\right)=\alpha\left|K_{\mathrm{DP}}\right|^{\beta}$} \\
\hline & \multicolumn{2}{|c|}{ MAE } & \multicolumn{2}{|c|}{ RMSE } & \multirow[t]{2}{*}{ Assumptions } \\
\hline & RADAR & 2DVD & RADAR & 2DVD & \\
\hline 1 & 6.04 & 0.69 & 6.99 & 0.93 & Pruppacher and Beard (1970) \\
\hline 2 & 7.69 & 0.75 & 8.63 & 0.99 & Beard and Chuang (1987) \\
\hline 3 & 8.67 & 0.76 & 9.62 & 1.00 & Brandes et al. (2002) \\
\hline 4 & 6.80 & 0.71 & 7.78 & 0.93 & New axis ratio (experimental fit) \\
\hline \multicolumn{6}{|c|}{$R\left(Z_{\mathrm{H}}, Z_{\mathrm{DR}}\right)=\alpha Z_{\mathrm{H}^{\beta}} 10^{0.1 \gamma} Z_{\mathrm{DR}}$} \\
\hline & \multicolumn{2}{|c|}{ MAE } & \multicolumn{2}{|c|}{ RMSE } & \multirow[t]{2}{*}{ Assumptions } \\
\hline & RADAR & 2DVD & RADAR & 2DVD & \\
\hline 1 & 0.89 & 0.66 & 1.22 & 0.92 & Pruppacher and Beard (1970) \\
\hline 2 & 0.85 & 0.69 & 1.18 & 0.96 & Beard and Chuang (1987) \\
\hline 3 & 0.87 & 0.73 & 1.20 & 1.02 & Brandes et al. (2002) \\
\hline 4 & 0.85 & 0.72 & 1.17 & 0.99 & New axis ratio (experimental fit) \\
\hline \multicolumn{6}{|c|}{$R\left(K_{\mathrm{DP}}, Z_{\mathrm{DR}}\right)=\alpha K_{\mathrm{DP}} 10^{0.1 \gamma} Z_{\mathrm{DR}}$} \\
\hline & \multicolumn{2}{|c|}{ MAE } & \multicolumn{2}{|c|}{ RMSE } & \multirow[t]{2}{*}{ Assumptions } \\
\hline & RADAR & 2DVD & RADAR & 2DVD & \\
\hline 1 & 8.19 & 0.58 & 10.05 & 0.88 & Pruppacher and Beard (1970) \\
\hline 2 & 10.92 & 0.61 & 12.98 & 0.91 & Beard and Chuang (1987) \\
\hline 3 & 12.71 & 0.64 & 14.96 & 0.94 & Brandes et al. (2002) \\
\hline 4 & 9.19 & 0.58 & 11.23 & 0.86 & New axis ratio (experimental fit) \\
\hline
\end{tabular}

$\left(\mathrm{MAE}=0.58 \mathrm{~mm} \mathrm{~h}^{-1}\right.$ and $\left.\mathrm{RMSE}=0.86 \mathrm{~mm} \mathrm{~h}^{-1}\right)$ when the $K_{\mathrm{DP}}$ and $Z_{\mathrm{DR}}$ parameters were used for 2DVD rainfall estimation (Fig. 7d). These results were influenced by the variability of the DSDs, and the effect of the DSD variability was worse in rainfall estimations obtained with the $R\left(K_{\mathrm{DP}}\right)$ or $R\left(K_{\mathrm{DP}}, Z_{\mathrm{DR}}\right)$ than those obtained with the $R\left(Z_{h}\right)$. However, if actual radar measurements were used, the $R\left(Z_{\mathrm{H}}, Z_{\mathrm{DR}}\right)$ algorithm showed the best performance, while the accuracy of radar rainfall estimation was reduced when the $K_{\mathrm{DP}}$ parameter was used. As shown in Fig. 8, at lower rain rates $\left(<10 \mathrm{~mm} \mathrm{~h}^{-1}\right), R\left(K_{\mathrm{DP}}\right)$ and $R\left(K_{\mathrm{DP}}, Z_{\mathrm{DR}}\right)$ were less efficient because the measured $K_{\mathrm{DP}}$ became too noisy; however, $R\left(K_{\mathrm{DP}}\right)$ and $R\left(K_{\mathrm{DP}}, Z_{\mathrm{DR}}\right)$ relations performed better than others at higher rain rates $\left(\geq 10 \mathrm{~mm} \mathrm{~h}^{-1}\right)$. Therefore, as the rain rate increased, the uncertainty in radar estimates due to the use of $K_{\mathrm{DP}}$ was reduced. $Z_{h}$ (instead of $K_{\mathrm{DP}}$ ) should be used jointly with $Z_{\mathrm{DR}}$ because $R\left(Z_{\mathrm{H}}, Z_{\mathrm{DR}}\right)$ showed excellent performance at lower rain rates. These results show that the $R\left(K_{\mathrm{DP}}, Z_{\mathrm{DR}}\right)$ relation will be useful for heavy rainfall, and $R\left(Z_{h}, Z_{\mathrm{DR}}\right.$ ) is more suited for light rainfall (Ryzhkov et al., 2005).

\subsubsection{Correction of calibration bias}

Radar measurements can suffer from $Z_{\mathrm{H}}$ and $Z_{\mathrm{DR}}$ system biases, and inaccurate calibration can lead to significant uncertainty in radar-based quantitative precipitation estimations. In this study, $Z_{\mathrm{H}}$ and $Z_{\mathrm{DR}}$ calibration biases were calculated for eight rainfall events through a comparison between $Z_{\mathrm{H}}$ and $Z_{\mathrm{DR}}$ radar measurements and $Z_{\mathrm{H}}$ and $Z_{\mathrm{DR}}$ simulations obtained from the 2DVD measurements. Figure $9 a$ and $b$ shows time series data for the 2DVD and BSL radar $Z_{\mathrm{H}}$ and 

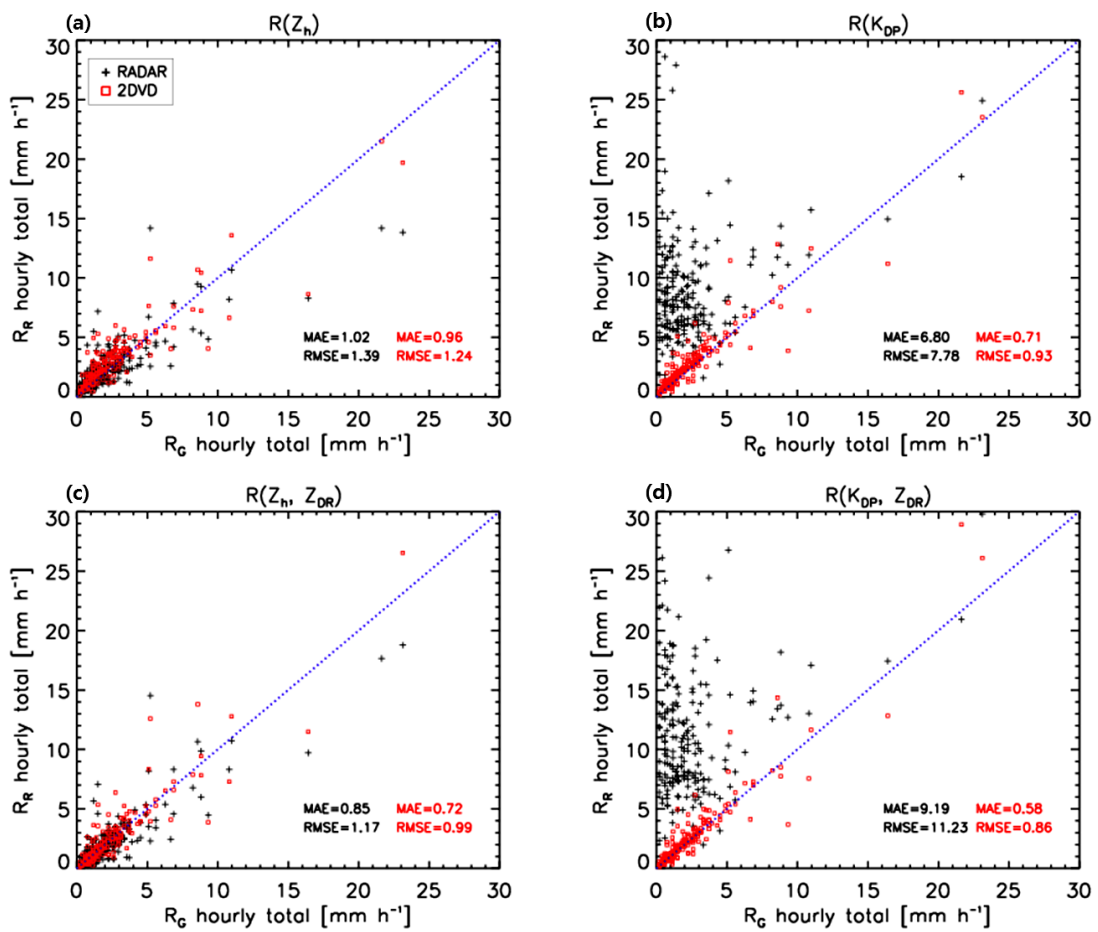

Figure 7. Scatter plot of the $1 \mathrm{~h}$ rain rate from rain gauge $\left(R_{\mathrm{G}}\right)$ and BSL S-band radar (or 2DVD) based on Eq. (4) for 18 rainfall cases. The pluses represents $1 \mathrm{~h}$ gauge rain rates vs. radar hourly rain rates from polarimetric rainfall algorithms, and squares indicate gauge and 2DVD rain rates obtained by different polarimetric rainfall algorithms.
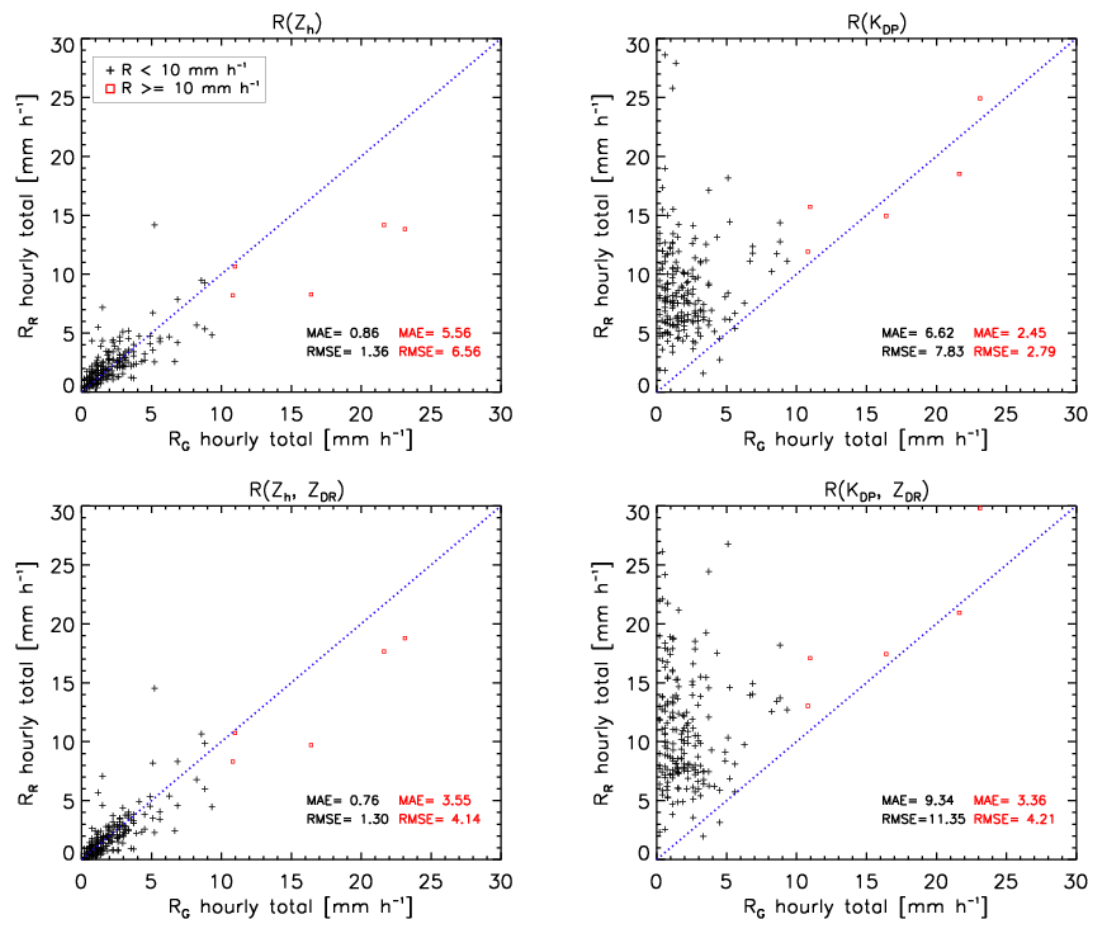

Figure 8. Scatter plots of the $1 \mathrm{~h}$ rain rates from rain gauge $\left(R_{\mathrm{G}}\right)$ and BSL S-band radar based on Eq. (4) for 18 rainfall cases. The pluses represents $1 \mathrm{~h}$ gauge rain rates vs. radar hourly rain rates from polarimetric rainfall algorithms for a light rain rate $\left(R<10 \mathrm{~mm} \mathrm{~h}^{-1}\right)$, and squares indicate those for a heavy rain rate $\left(R \geq 10 \mathrm{~mm} \mathrm{~h}^{-1}\right)$. 

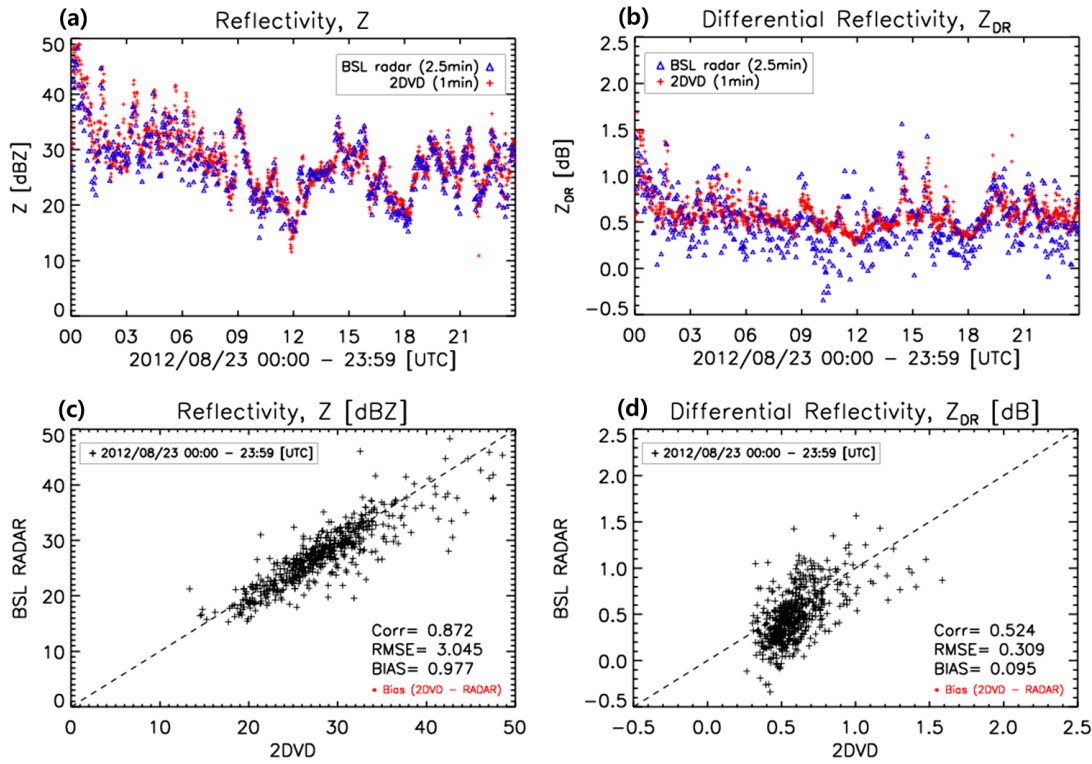

(d) Differential Reflectivity, $\mathrm{Z}_{\mathrm{OR}}[\mathrm{dB}]$

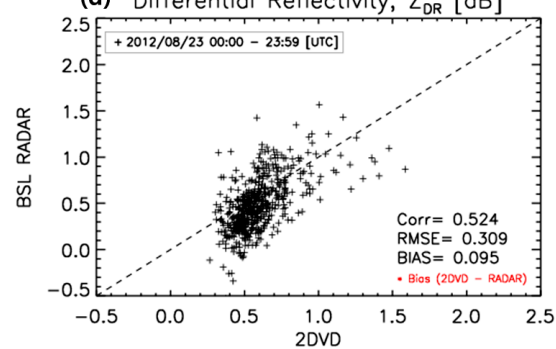

Figure 9. Time series of the (a) reflectivity and (b) differential reflectivity obtained by 2DVD and BSL S-band radar, and scatter plots of the 2DVD estimations and radar measurements for the (c) reflectivity and (d) differential reflectivity. Comparison statistics including the correlation coefficient (Corr), RMSE, and bias are also presented (measurements were collected on 23 August 2012).
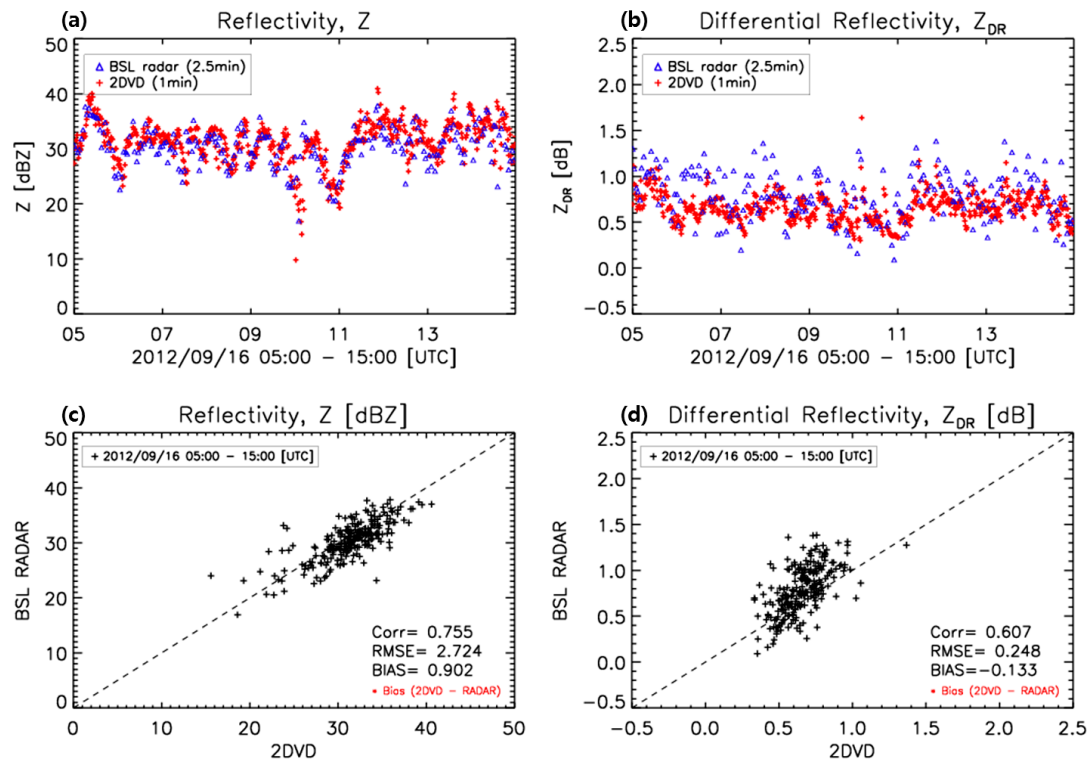

Figure 10. Same as Fig. 9, except that the data are for 16 September 2012.

$Z_{\mathrm{DR}}$, and Fig. $9 \mathrm{c}$ and $\mathrm{d}$ shows scatter plots of the 2DVD estimations and radar measurements for the $Z_{\mathrm{H}}$ and $Z_{\mathrm{DR}}$ on 23 August 2012. The overall distribution of the observed $Z_{\mathrm{H}}$ corresponded well with the simulated parameter; however, the BSL $Z_{\mathrm{DR}}$ measurements were underestimated with respect to the simulated $Z_{\mathrm{DR}}$ values. The mean bias (= bias) of $Z_{\mathrm{H}}$ and $Z_{\mathrm{DR}}$ was about $0.98 \mathrm{dBZ}$ and $0.10 \mathrm{~dB}$, respectively. The bias of $Z_{\mathrm{H}}$ and $Z_{\mathrm{DR}}$ on 16 September 2012 was $0.90 \mathrm{dBZ}$ and $-0.13 \mathrm{~dB}$, respectively (Fig. 10).
The application of absolute calibration biases is the most effective way to reduce radar rainfall errors, in particular, for rainfall estimators with both $Z_{\mathrm{H}}$ and $Z_{\mathrm{DR}}$ (Kwon et al., 2015). The accuracy of the radar rainfall estimations was investigated by applying the calculated $Z_{\mathrm{H}}$ and $Z_{\mathrm{DR}}$ bias. The $R\left(Z_{h}, Z_{\mathrm{DR}}\right)$ algorithm based on the new mean axis-ratio relation showed the best result in terms of radar rainfall estimations. These results were evaluated by comparison with rain gauge measurements, which represent the ground truth situ- 
Table 5. Mean absolute error (MAE) and root-mean-square error (RMSE) of rainfall estimates before and after applying bias correction.

\begin{tabular}{|c|c|c|c|c|c|c|c|c|c|c|}
\hline \multirow[b]{2}{*}{$(\mathrm{dBZ})$} & \multirow[b]{2}{*}{$(\mathrm{dB})$} & \multicolumn{2}{|c|}{$\begin{array}{l}\text { Calibration } \\
\text { bias }\end{array}$} & \multicolumn{2}{|c|}{$\begin{array}{c}\text { Radar rainfall } \\
\text { estimation }\end{array}$} & \multirow{2}{*}{$\begin{array}{c}\begin{array}{c}\text { Rain } \\
\text { gauge }\end{array} \\
\text { Obs. } \\
\text { BC }\end{array}$} & \multicolumn{2}{|c|}{$\begin{array}{c}\text { MAE } \\
\left(\mathrm{mm} \mathrm{h}^{-1}\right)\end{array}$} & \multicolumn{2}{|c|}{$\begin{array}{c}\text { RMSE } \\
\left(\mathrm{mm} \mathrm{h}^{-1}\right)\end{array}$} \\
\hline & & $\begin{array}{l}Z_{h} \\
\mathrm{BC}\end{array}$ & $\begin{array}{r}Z_{\mathrm{DR}} \\
\mathrm{BC}\end{array}$ & Before & $\begin{array}{c}\text { After } \\
\text { BC }\end{array}$ & & $\begin{array}{c}\text { Before } \\
\text { BC }\end{array}$ & $\begin{array}{l}\text { After } \\
\text { BC }\end{array}$ & Before & After \\
\hline 1 & 11.10 .13 & -0.01 & 0.10 & 20.71 & 18.99 & 16.85 & 0.50 & 0.40 & 0.61 & 0.49 \\
\hline 2 & 11.10 .21 & 1.16 & 0.28 & 48.60 & 48.26 & 49.96 & 0.77 & 0.76 & 0.99 & 0.98 \\
\hline 3 & 12.04 .25 & 1.40 & 0.43 & 19.83 & 18.07 & 17.24 & 1.33 & 1.24 & 2.03 & 1.90 \\
\hline 4 & 12.05 .14 & 2.17 & 0.28 & 12.89 & 15.58 & 19.40 & 0.57 & 0.42 & 0.78 & 0.58 \\
\hline 5 & 12.08 .23 & 0.98 & 0.10 & 72.65 & 81.35 & 83.86 & 0.78 & 0.62 & 1.27 & 0.87 \\
\hline 6 & 12.09 .09 & 0.44 & 0.18 & 18.16 & 17.00 & 14.17 & 0.75 & 0.68 & 1.18 & 1.09 \\
\hline 7 & 12.09 .16 & 0.90 & -0.13 & 44.90 & 53.77 & 55.20 & 0.75 & 0.69 & 0.92 & 0.84 \\
\hline \multirow[t]{2}{*}{8} & 12.10 .22 & -1.44 & -0.14 & 18.55 & 15.76 & 14.92 & 2.85 & 2.60 & 3.49 & 3.30 \\
\hline & Avg & 1.03 & 0.22 & & & & 1.04 & 0.93 & 1.41 & 1.26 \\
\hline
\end{tabular}

*BC: bias correction.
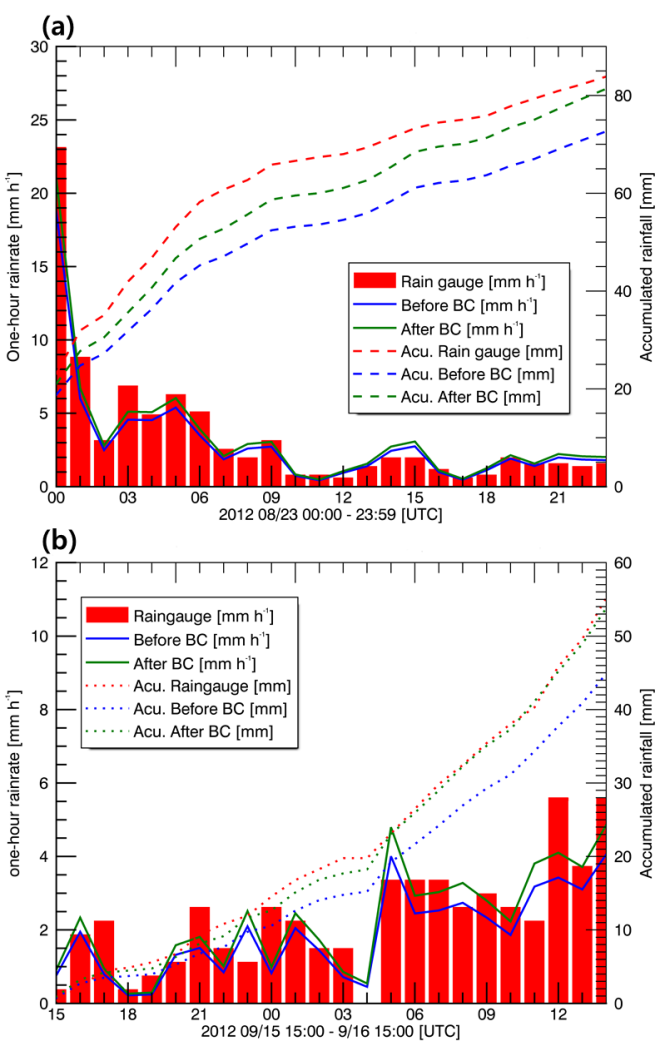

Figure 11. Comparison of the $1 \mathrm{~h}$ rain rate (left ordinate) and accumulated rainfall (right ordinate) obtained by the BSL S-band radar and rain gauge. The $R\left(Z_{\mathrm{H}}, Z_{\mathrm{DR}}\right)$ algorithm based on Eq. (4) was used for rainfall estimations for (a) 23 August 2012 and (b) 16 September 2012. BC represents the bias correction.

ation. Figure 11a shows the $1 \mathrm{~h}$ rain rate (left ordinate) and accumulated rainfall (right ordinate) estimated from the radar and rain gauge on 23 August 2012. The blue and green solid lines are estimated $1 \mathrm{~h}$ rainfall rates obtained before and after bias correction, respectively. The bar graph is the $1 \mathrm{~h}$ rainfall rate measured by the rain gauge. The blue and green dashed lines are estimated accumulated rainfall obtained before and after the bias correction, respectively, and the red dashed line is the accumulated rainfall measured by the rain gauge. In comparison with the rain gauge measurement $(83.86 \mathrm{~mm})$, the underestimated precipitation $(72.65 \mathrm{~mm})$ was corrected to $81.35 \mathrm{~mm}$ after bias correction. When the estimated rainfall was compared to the rain gauge data, rainfall estimation was improved by about $10.38 \%$. Figure $11 \mathrm{~b}$ shows the results for the 16 September 2012 event. The recorded accumulated rainfall amounts were $55.20,44.90$, and $53.77 \mathrm{~mm}$ for the rain gauge, radar before bias correction, and radar after bias correction results, respectively. The radar rainfall estimation was improved by about $16.07 \%$. For the eight considered rainfall events, the $Z_{\mathrm{H}}$ and $Z_{\mathrm{DR}}$ total mean biases for the $\mathrm{BSL}$ radar was $1.03 \mathrm{dBZ}$ and $0.22 \mathrm{~dB}$, respectively. Moreover, MAE changed from 1.04 to $0.93 \mathrm{~mm} \mathrm{~h}^{-1}$ and RMSE decreased from 1.41 to $1.26 \mathrm{~mm} \mathrm{~h}^{-1}$ after the bias correction. The bias of $Z_{\mathrm{H}}$ and $Z_{\mathrm{DR}}$ as well as MAE and RMSE values for each of the eight rainfall events are presented in Table 5. As shown in Table 5, both MAE and RMSE values decreased after the bias correction, which, therefore, lead to an improvement of rainfall estimation.

\section{Conclusions}

The purpose of this study was to find an optimal polarimetric rainfall algorithm by using 2DVD measurements in Korea, and to improve the radar rainfall estimations by correcting the $Z_{\mathrm{H}}$ and $Z_{\mathrm{DR}}$ biases. First, we derived a new raindrop axisratio relation reflecting the rainfall characteristics on the Korean Peninsula by using data from 33 rainfall events, and this was done after checking the accuracy and performing a quality control procedure for the 2DVD measurements. The derived raindrop axis-ratio relation was compared with existing 
relations. The derived new mean axis-ratio relation was very similar to existing axis-ratio relations except for both small particles $(\leq 2 \mathrm{~mm})$ and large particles $(\geq 5.5 \mathrm{~mm})$. The dependence of the raindrop axis ratio on climatic regimes was not clearly observed.

The polarimetric rainfall algorithms were derived based on various assumptions about the shape of raindrops. The accuracy validation of the $1 \mathrm{~h}$ rainfall rate obtained through rainfall algorithms was assessed by comparing 2DVD and BSL radar data with rain gauge measurements. As a result, $R\left(K_{\mathrm{DP}}, Z_{\mathrm{DR}}\right)$ based on the new axis-ratio relation was deemed suitable for rainfall estimations according to the DSD statistics when compared with others. This occurs because the effect of the DSD variability declined in rainfall estimations obtained with the $R\left(K_{\mathrm{DP}}\right)$ or $R\left(K_{\mathrm{DP}}, Z_{\mathrm{DR}}\right)$ compared to those obtained with the $R\left(Z_{h}\right)$. However, if actual radar measurements were used, at lower rain rates $\left(<10 \mathrm{~mm} \mathrm{~h}^{-1}\right)$, the $K_{\mathrm{DP}}$-based algorithms displayed large statistical errors, while $R\left(Z_{h}, Z_{\mathrm{DR}}\right)$ based on the new axisratio relation showed the best performance. This occurs because the measured $K_{\mathrm{DP}}$ parameter was relatively noisy at lower rain rates. However, the $R\left(K_{\mathrm{DP}}, Z_{\mathrm{DR}}\right)$ algorithm based on the new axis-ratio relation performed better than the others at higher rain rates $\left(\geq 10 \mathrm{~mm} \mathrm{~h}^{-1}\right)$. Therefore, in order to produce more accurate rainfall estimations, the $R\left(Z_{h}, Z_{\mathrm{DR}}\right)$ and $R\left(K_{\mathrm{DP}}, Z_{\mathrm{DR}}\right)$ algorithm should be classified according to rainfall intensities.

To perform radar calibration measured $Z_{\mathrm{H}}$ and $Z_{\mathrm{DR}}$ were compared with simulated $Z_{\mathrm{H}}$ and $Z_{\mathrm{DR}}$. The calculated $Z_{\mathrm{H}}$ and $Z_{\mathrm{DR}}$ bias was used to reduce radar bias, and to produce more accurate rainfall estimations. After bias correction, radar rainfall estimations were closer to rain gauge measurements, meaning an improvement of the first ones.

In this paper, different raindrops axis ratios were used to derive new polarimetric rainfall relations, and the new polarimetric rainfall algorithms were assessed with respect to their ability to produce accurate point radar rainfall estimations. The new polarimetric rainfall algorithms performed better than existing rainfall algorithms, and no large differences were observed in regard to climatic regimes. In particular, the use of the $R\left(Z_{h}, Z_{\mathrm{DR}}\right)$ algorithm lead to an improvement of radar rainfall estimations in the Korean Peninsula since in this region extreme precipitation systems such as tornados, supercells, and hail storms do not often occur. We are now working to improve the $K_{\mathrm{DP}}$ quality because it is a very useful parameter for high rainfall rates estimation. A classification of rain rates based on these results will also be performed in future work. In addition, polarimetric rainfall algorithms will be developed to obtain areal rainfall estimations through long-term DSD collection efforts and several rainfall-cases-based analyses.

Acknowledgements. This research was supported by the "Development and application of cross governmental dual-pol radar harmonization (WRC-2013-A-1)" project of the Weather Radar Center, Korea Meteorological Administration.

Edited by: G. Vulpiani

Reviewed by: S. Sebastianelli and four anonymous referees

\section{References}

Adirosi, E., Gorgucci, E., Baldini, L., and Tokay, A.: Evaluation of gamma raindrop size distribution assumption through comparison of rain rates of measured and radar-equivalent gamma DSD, J. Appl. Meteorol. Clim., 53, 1618-1635, 2014.

Atlas, D.: Radar calibration: some simple approaches, B. Am. Meteorol. Soc., 83, 1013-1316, 2002.

Atlas, D., Srivastava, R. C., and Sekkon, R. S.: Doppler radar characteristics of precipitation at vertical incidence, Rev. Geophys. Space Ge, 2, 1-35, 1973.

Beard, K. B. and Chuang, C.: A new model for the equilibrium shape of raindrops, J. Atmos. Sci., 44, 1509-1524, 1987.

Brandes, E. A., Zhang, G., and Vivekanandan, J.: Experiments in rainfall estimation with a polarimetric radar in a subtropical environment, J. Appl. Meteorol., 41, 674-685, 2002.

Bringi, V. N. and Chandrasekar, V.: Polarimetric Doppler Weather Radar: Principles and Applications, Cambridge University Press, New Yprk, USA, p. 636, 2001.

Bringi, V. N., Chandrasekar, V., Hubbert, J., Gorgucci, E., Randeu, W. L., and Schoenhuber, M.: Raindrop size distribution in different climatic regimes from disdrometer and dual-polarized radar analysis, J. Atmos. Sci., 60, 354-365, 2003.

Chandrasekar, V., Bringi, N., Balakrishnan, and Zrnić, D. S.: Error structure of multiparameter radar and surface measurements of rainfall, Part III: Specific differential phase, J. Appl. Meteorol., 32, 1288-1293, 1990.

Chang, W. Y., Wang, T. C., and Lin, P. L.: Characteristics of the raindrop size distribution and drop shape relation in typhoon systems in the western Pacific from the 2D video disdrometer and NCU C-band polarimetric radar, J. Atmos. Ocean. Tech., 26, 19731993, 2009.

Cifelli, R., Chandrasekar, V., Lim, S., Kennedy, P. C., Wang, Y., and Rutledge, S. A.: A new dual-polarization radar rainfall algorithm: Application in Colorado precipitation events, J. Atmos. Ocean. Tech., 28, 352-364, 2011.

Goddard, J. W. F. and Cherry, S. M.: The ability of dual-polarization radar (copular linear) to predict rainfall rate and microwave attenuation, Radio Sci., 19, 201-208, 1984.

Goddard, J. W. F., Cherry, S. M, and Bringi, V. N.: Comparison of dual-polarized radar measurements of rain with groundbased disdrometer measurements, J. Appl. Meteorol., 21, 252256, 1982.

Gorgucci, E., Scarchilli, G., Chandrasekar, V., and Bringi, V. N.: Rainfall estimation from polarimetric radar measurements: Composite algorithms immune to variability in raindrop shape-size relation, J. Atmos. Ocean. Tech., 18, 1773-1786, 2001.

Green, A. W.: An approximation for the shapes of large rain-drops, J. Appl. Meteorol., 14, 1578-1583, 1975.

Hagen, M. and Yuter, S. E.: Relations between radar reflectivity, liquid water content, and rainfall rate during the MAPSOP, Q. J. Roy. Meteor. Soc., 129, 477-493, 2003. 
Huang, G. J., Bringi, V. N., and Thurai, M.: Orientation angle distributions of drops after an 80-m fall using a 2D video disdrometer, J. Atmos. Ocean. Tech., 25, 1717-1723, 2008.

Jameson, A. R.: Microphysical interpretation of multiparameter radar measurements in rain, Part I: Interpretation of polarization measurements and estimation of raindrop shapes, J. Atmos. Sci., 40, 1792-1802, 1983.

Jameson, A. R.: Microphysical interpretation of multiparameter radar measurements in rain, Part III: Interpretation and measurement of propagation differential phase shift between orthogonal linear polarizations, J. Atmos. Sci., 42, 607-614, 1985.

Joss, J., Thams, J. C., and Waldvogel, A.: The accuracy of daily rainfall measurements by radar, In: pre-prints, 13th Radar Meteorology Conf., Montreal, QC, Canada, Amer. Meteor. Soc., 448451, 1968

Jung, Y., Xue, M., and Zhang, G.: Simulations of polarimetric radar signatures of a supercell storm using a two-moment bulk microphysics scheme, J. Appl. Meteorol. Clim., 49, 146-163, 2010.

Keenan, T. D., Carey, L. D., Zrnić, D. S., and May, P. T.: Sensitivity of 5-cm wavelength polarimetric radar variables to raindrop axial ratio and drop size distribution, J. Appl. Meteorol., 40, 526-545, 2001.

Kruger, A. and Krajewski, W. F.: Two-dimensional video disdrometer, J. Atmos. Sci., 19, 602-617, 2002.

Kwon, S., Lee, G. W., and Kim, G.: Rainfall estimation from an operational S-band dual-polarization radar: Effect of radar calibration, J. Meteorol. Soc. Jpn., 93, 65-79, 2015.

Maki, M., Park, S. G., and Bringi, V. N.: Effect of natural variations in raindrop size distributions on rain rate estimators of $3 \mathrm{~cm}$ wavelength polarimetric radar, J. Meteorol., Soc. Jpn., 83, 871893, 2005.

Marzuki, M., Randeu, W. L., Kozu, T., Shimomai, T., Hashiguchi, H., and Schonhuber, M.:Raindrop axis ratios, fall velocities and size distribution over Sumatra from 2D-Video Disdrometer measurement, Atmos. Res., 119, 23-37, 2013.

McFarquhar, G. M. and List, R.: The effect of curve fits for the disdrometer calibration on raindrop spectra, rainfall rate, and radar reflectivity, J. Appl. Meteorol., 32, 774-782, 1993.

Park, S. G. and Lee, G. W.: Calibration of radar reflectivity measurements from the KMA operational radar network, Asian-Pacific J. Atmos. Sci., 46, 243-259, 2010.

Pruppacher, H. and Beard, K. V.: A wind tunnel investigation of the internal circulation and shape of water drops falling at terminal velocity in air, Q. J. Roy. Meteor. Soc., 96, 247-256, 1970.

Pruppacher, H. R. and Pitter, R.: A semi-empirical determination of the shape of cloud and rain drops, J. Atmos. Sci, 28, 86-94, 1971.
Raupach, T. H. and Berne, A.: Correction of raindrop size distributions measured by Parsivel disdrometers, using a twodimensional video disdrometer as a reference, Atmos. Meas. Tech., 8, 343-365, doi:10.5194/amt-8-343-2015, 2015.

Ryzhkov, A. V. and Zrnić, D. S.: Comparison of dual-polarization radar estimators of rain, J. Atmos. Ocean. Tech., 12, 249-256, 1995.

Ryzhkov, A. V., Giangrande, S. E., and Schuur, T. J.: Rainfall estimation with a polarimetric prototype of WSR-88D, J. Appl. Meteorol., 44, 502-515, 2005.

Sachidananda, M. and Zrnić, D. S.: Rain rate estimates from differential polarization measurements, J. Atmos. Ocean. Tech., 4, 588-598, 1987.

Sebastianelli, S., Russo, F., Napolitano, F., and Baldini, L.: On precipitation measurements collected by a weather radar and a rain gauge network, Nat. Hazards Earth Syst. Sci., 13, 605-623, doi:10.5194/nhess-13-605-2013, 2013.

Sheppard, B. E. and Joe, P. I.: Comparison of raindrop size distribution measurements by a Joss-Waldvogel disdrometer, a PMS 2DG spectrometer, and a POSS Doppler radar, J. Atmos. Ocean. Tech., 11, 874-887, 1994.

Thurai, M. and Bringi, V. N.:Drop axis ratios from a 2D video disdrometer, J. Atmos. Ocean. Tech., 22, 966-978, 2005.

Tokay, A. and Short, D. A.: Evidence from tropical raindrop spectra of the origin of rain from stratiform versus convective clouds, J. Appl. Meteorol., 35, 355-371, 1996.

Tokay, A., Wolff, D. B., Wolff, K. R., and Bashor, P.: Rain gauge and disdrometer measurements during the Keys Area Microphysics Project (KAMP), J. Atmos. Ocean. Tech., 20, 1460-1477, 2003.

Ulbrich, C. W.: Natural variations in the analytical form of the raindrop size distribution, J. Clim. Appl. Meteorol., 22, 1764-1775, 1983.

Ulbrich, C. W. and Lee, L. G.: Rainfall measurement error by WSR$88 \mathrm{D}$ radars due to variations in $\mathrm{Z}-\mathrm{R}$ law parameters and the radar constant, J. Atmos. Ocean. Tech., 16, 1017-1024, 1999.

Villarini, G. and Krajewski, W. F.: Review of the different sources of uncertainty in single polarization radar-based estimates of rainfall, Surv. Geophys., 31, 107-129, 2010.

Zawadzki, I.: Factors affecting the precision of radar measurements of rain, In: Preprints, 22nd Radar Meteorology Conference, September 10-13, Zurich, Switzerland, Boston, MA, Amer. Meteor. Soc., 251-256, 1984.

Zhang, G., Vivekanandan, J., and Brandes, E.: A method for estimating rain rate and drop size distribution from polarimetric radar measurements, IEEE T. Geosci. Remote, 39, 830-841, 2001. 